\title{
A model tool for assessing real-time mixing of mineral and anthropogenic pollutants in East Asia: a case study of April 2005
}

\author{
F. Lasserre ${ }^{1}$, G. Cautenet ${ }^{1}$, C. Bouet ${ }^{1}$, X. Dong ${ }^{2}$, Y. J. Kim ${ }^{3}$, N. Sugimoto ${ }^{4}$, I. Matsui ${ }^{4}$, and A. Shimizu ${ }^{4}$ \\ ${ }^{1}$ Laboratoire de Météorologie Physique, Université Blaise Pascal, Complexe scientifique des Cézeaux, BP 45, 63170, \\ Aubière, France \\ ${ }^{2}$ Sino-Japan Friendship Center for Environmental Protection, Beijing 100029, China \\ ${ }^{3}$ Advanced Environment Monitoring Research Center, Department of Environmental Science and Engineering, Gwangju \\ Institute of Science and Technology, 1 Oryong-dong, Gwangju 500-712, Korea \\ ${ }^{4}$ National Institute for Environmental Studies, 16-2 Onogawa, Tsukuba, Ibaraki 305-8506, Japan
}

Received: 4 June 2007 - Published in Atmos. Chem. Phys. Discuss.: 14 August 2007

Revised: 3 June 2008 - Accepted: 6 June 2008 - Published: 9 July 2008

\begin{abstract}
In order to assess the complex mixing of atmospheric anthropogenic and natural pollutants over the East Asian region, we present a modelling tool which takes into account the main aerosols which are to be found simultaneously over China, Korea and Japan during springtime. Using the mesoscale RAMS (Regional Atmospheric Modeling System) tool, we present a simulation of natural (desert) dust events along with some of the most critical anthropogenic pollutants over East Asia, sulphur elements $\left(\mathrm{SO}_{2}\right.$ and $\left.\mathrm{SO}_{4}^{2-}\right)$ and Black Carbon (BC).
\end{abstract}

As regards a one-week case study of dust events which occurred during late April 2005 over an area extending from the Gobi deserts to the Japan surroundings, we satisfactorily model the behaviours of the different aerosol plumes. We focus on possible dust mixing with the anthropogenic pollutants from megacities. For both natural and anthropogenic pollution, the model results are in fairly good agreement with the horizontal and vertical distributions of concentrations as measured by in situ LIDAR, and as observed in remote data, $\mathrm{PM}_{10}$ data and literature. In particular, we show that a simplified chemistry approach of this complex issue is sufficient to model this event, with a real-time step of $3 \mathrm{~h}$. The model reproduces the main patterns and orders of magnitude for Aerosol Optical Thickness (AOT) and species contributions (via the Angström Exponent) when compared with the AErosol RObotic NETwork (AERONET) data.

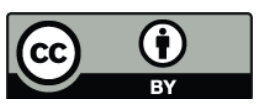

Correspondence to: G. Cautenet (g.cautenet@opgc.univ-bpclermont.fr)

\section{Introduction}

Anthropogenic pollution is a permanent element of the climate over Asian megacities and the surrounding countries. Moreover, these areas are also subjected to natural pollutions from mineral origin, when a desert dust storm occurs (Sun et al., 2001). Thus, mainly during springtime, aerosol plumes from natural and anthropogenic origins can coexist over Northern China, Korea and Japan. It is thus necessary to take the anthropogenic aerosol into account along with the natural aerosol in order to have a correct view of the Asian aerosol system.

Sandstorms occurring over East Asia during springtime and summertime are characterised by mineral dust and particles containing sulphur elements (Tang et al., 2004; Liu et al., 2005). Carbonaceous aerosols are also often mixed with mineral dust as shown for example by Shi et al. (2003) in Beijing. The sulphur emissions due to industrial activities are particularly important in China. Black Carbon (BC) particles are less concentrated than $\mathrm{SO}_{2}$ and its derivatives, but they also induce harmful pollution as regards human health; and they affect the atmospheric processes: physical (direct and indirect effects), chemical (as sufficiently subdivided elements, they support $\mathrm{SO}_{2} \rightarrow \mathrm{SO}_{4}^{2-}$ conversion; Novakov et al., 1974) and photochemical processes. $\mathrm{BC}$ aerosols are consequently studied in order to preserve public health and to better understand regional and global climatic changes (Chylek et al., 1995; Jacobson, 2001; Menon et al., 2002).

The objective of this article is to present a simplified but realistic way to model the roles of the main anthropogenic pollutants in the total pollution. We therefore purposely

Published by Copernicus Publications on behalf of the European Geosciences Union. 
simplify the problem and consider a very restricted number of anthropogenic pollutants focusing only on some of the most representative ones, as regards optical properties issues.

We use a mesoscale model coupled with special modules accounting for the sources of natural (desert dust) and anthropogenic pollutants. We examine the atmospheric cycle of these pollutants over a few days, with a sufficiently short time step to take into account the strong variability of that kind of event "in real time". In this case study, we give details about the possible interactions of anthropogenic pollutants with the mineral aerosols carried along by a sandstorm of "medium" intensity (i.e. the most standard events). Therefore, we compare the modelled plumes with remote (satellite, LIDAR) and surface data along with surface data of Aerosol Optical Thickness (AOT).

We do not try to retrieve a tremendous dust storm like the storms of exceptional intensities of 19 April 1998 or 20 March 2002. The uplifted masses during the severe dust storms are of great interest, but, in terms of frequency, the severe dust storms are only a minor fraction of the dust polluting events. It is challenging to deal with that kind of "common" storm and to compare the instantaneous model outputs with observational data because these short moderate sandstorms induce most of the dusty days in China, as observed and modelled by Laurent et al. (2005).

A description of the model parameters is presented in section 2. The quantitative datasets used to compare the modelled aerosol plumes with the observations are detailed in Sect. 3. Section 4 shows the different model results according to desert dust flux budgets and the resulting plumes. It provides details about the mixing between mineral dust and sulphur aerosols on the regional scale. Moreover, section 4 focuses on local studies over two Chinese cities (Hohhot and Beijing), which are representative of the aerosols pathways. We particularly highlight the use of the AERONET (AErosol RObotic NETwork, Holben et al., 1998) data (http: //aeronet.gsfc.nasa.gov/) to validate the efficiency of our simplified approach of this complex issue concerning China, Korea and Japan.

\section{The model tools}

\subsection{A short description of the RAMS mesoscale model}

We use the parallelized mesoscale Regional Atmospheric Modeling System (RAMS) model version 4.3.0 developed by the Colorado State University (Cotton et al., 2003). It is an eulerian, non-hydrostatic meteorological model featuring powerful facilities such as 4DDA (four dimensional data assimilation), interactive 2-way nesting (up to 8 grids), bulk or detailed microphysics ( 7 hydrometeors) and a comprehensive surface model. The RAMS model is initialized and laterally nudged (every $6 \mathrm{~h}$ ) by the European Center for Mediumrange Weather Forecasts (ECMWF) analysis fields. In order to accurately represent the atmospheric cycles of aerosols, the RAMS model is coupled with natural and anthropogenic aerosol schemes (sources/sinks), as described in $\$ 2.2,2.3$ and 2.4.

The model grid is centered on $(40 \mathrm{~N}, 108 \mathrm{E})$ and extends (with stereopolar projection) from $(26 \mathrm{~N}, 79 \mathrm{E})$ to $(45 \mathrm{~N}$, 145E). There are 235 gridpoints in longitude and 95 in latitude, with a grid mesh of $25 \mathrm{~km}$. On the vertical dimension, there are 30 levels, from the surface to about $22 \mathrm{~km}$ in expanding spacing (including 10 vertical levels from the surface to about $1.2 \mathrm{~km}$ ). The simulation starts on 25 April 2005, 00:00 UTC, in order to give $48 \mathrm{~h}$ for the field to be initialized. The time step used in the computations is $10 \mathrm{sec}-$ onds. This low value is necessary for the numerical stability due to the presence of severe reliefs (Tibet and Pamir) in the South and West of the modelled area. Simulation is carried out on 64 parallel processors and approximately needs $30 \mathrm{~h}$ in CPU time.

\subsection{Desert dust processing}

As regards desert dust, the aerosol flux is provided by the Dust Production Model (hereafter referred to as DPM) developed by Marticorena and Bergametti (1995), Marticorena et al. (1997a, 1997b) and by Alfaro et al. (1998), Alfaro and Gomes (2001). In this DPM scheme (Marticorena et al., 1997a, 1997b; Alfaro and Gomes, 2001), the dust flux at a given grid point is the consequence of all the contributions of the various soil natures constituting the surface represented by this point. At a given grid point, and for each kind of soil type, dust flux is calculated using a set of physical parameters, the most important being the surface roughness and the percentage of erodibility. We have previously selected the values of these parameters as detailed in the study of a mineral dust storm which occurred in North-Eastern China, during spring 2002 (Lasserre et al., 2005).

Figure 1 presents the soil types' map used in this study. The surface map is brought up to date, in terms of erodibility, according to the snow-cover at the end of April 2005. As the snow-covered areas are primarily limited to the reliefs, we actually obtain a map (Fig. 2) of the real erodibilities "superimposable" on the soil types' map. Figure 2 specifies the zones referred to as 1, 2 and 3 from now on. Zone 3 (38$50 \mathrm{~N}, 94-119 \mathrm{E})$ concerns the overall North-East of the map, including zone 1 and zone 2, but also the non emissive pixels.

The DPM has been coupled online to the RAMS model (online means that the wind speed used as DPM input is provided by the RAMS model itself). At every time step and every grid point, the DPM calculates the amount of mobilized dust, which is then redistributed in the first model levels. We use a spectral representation of dust granulometry, i.e. the dust mass flux is redistributed over 20 size classes (20 discrete bins) with radius values ranging from $0.1 \mu \mathrm{m}$ to $13 \mu \mathrm{m}$. The spectrum has three lognormal mass components with radii of $0.75 \mu \mathrm{m}, 3.35 \mu \mathrm{m}$ and $7.1 \mu \mathrm{m}$, and logarithmic 


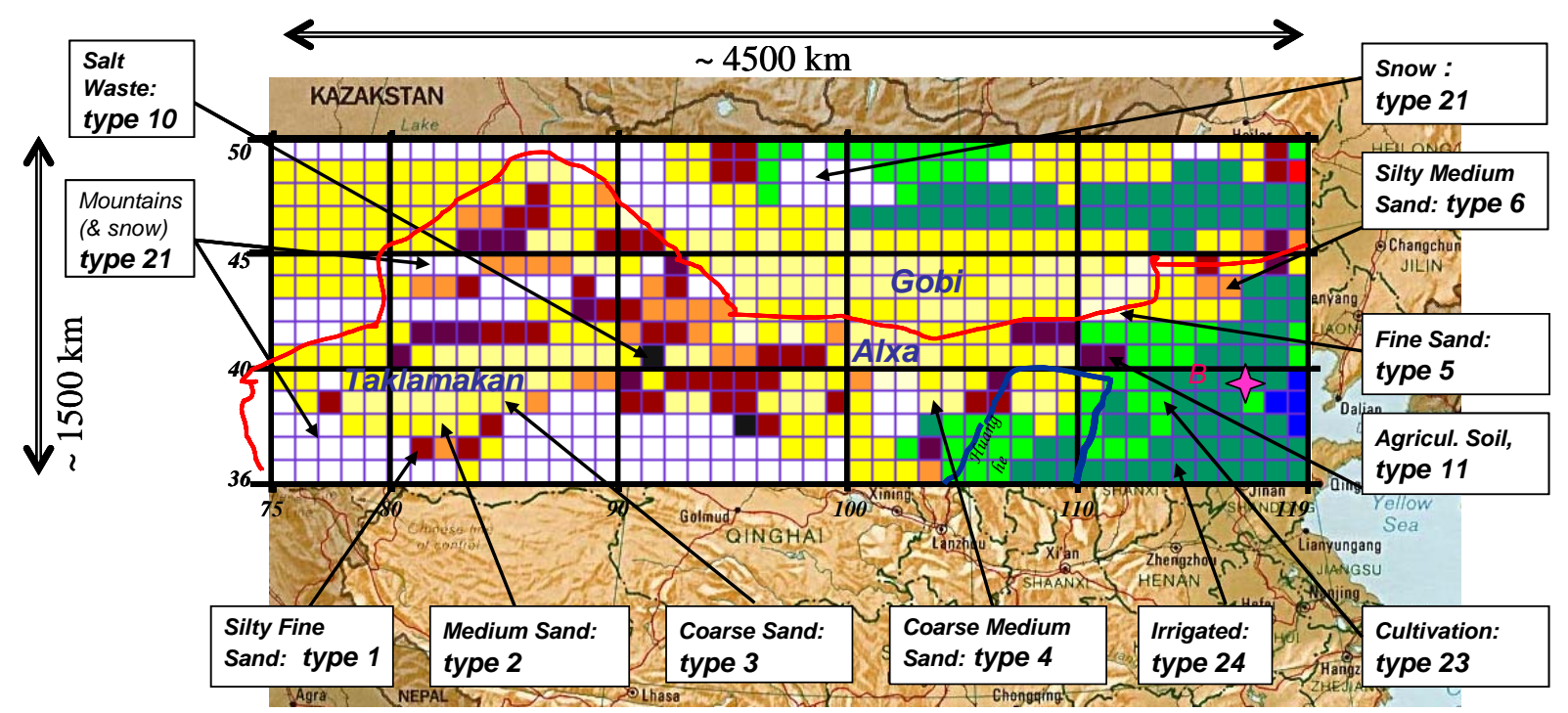

Fig. 1. Map of the DPM soil types for Northern China and Mongolia. Codes are the typology of Marticorena and Bergametti (1995) and are shown on some places. The red line indicates the northern border of China. Beijing city (B, pink star), Huang He River (rough blue line), Gobi Desert, Alxa plateau and Taklamakan Desert are also located.

standard deviations of $1.7,1.6$ and 1.5. The respective weights of each mode in the initial spectrum, i.e. during dust rise and before any deposition, are governed by the available kinetic energy of the saltating aggregates (Alfaro et al., 1998; Alfaro and Gomes, 2001). The mineral aerosol density is assumed to be $2650 \mathrm{~kg} \mathrm{~m}^{-3}$ (Marticorena and Bergametti, 1995). Each dust class is then diffused by turbulence, advected in the three dimensions and deposited by wet removal (Cautenet and Lefeivre, 1994), and by dry removal (gravitational deposition) according to Cautenet et al. (2000). Dust particles with radii larger than $13 \mu \mathrm{m}$ are not much involved in long range transport because of quick gravitational settling. The sedimentation of a $13 \mu \mathrm{m}$ radius dust particle is $6 \mathrm{~cm} \mathrm{~s}^{-1}$ (the sedimentation of a $20 \mu \mathrm{m}$ radius dust particle is faster than $10 \mathrm{~cm} \mathrm{~s}^{-1}$ ). We observe that these large mineral particles can reach the anthropogenic pollutant sources when they are close to the desert areas. However, the largest dust particles have a weak impact on AOT when compared with the one of the submicronic mode, due to their (relative) small number and, therefore, to their relatively weak specific extinction surface (when compared with the global surface, including all bin sizes). Moreover, large mineral particles won't reach the main $\mathrm{SO}_{2}$ and $\mathrm{BC}$ sources of the eastern part of the studied area.

For all these processes except removal, we have used the built-in "inert tracer" facility of the RAMS model: this scheme provides advection and diffusion of any passive scalar.

The coupling of the dust scheme with RAMS is described in Cautenet et al. (2000), Pradelle and Cautenet (2002), Minvielle et al. (2004a; 2004b) and in Lasserre et al. (2005).

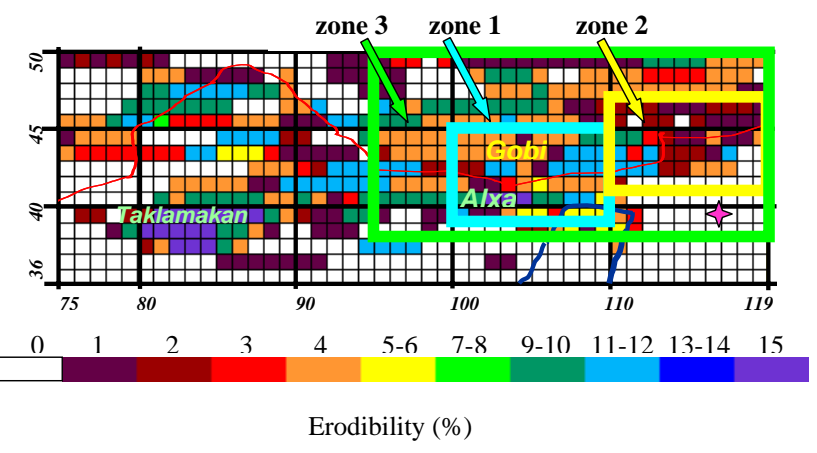

Fig. 2. Map of the DPM erodibilities (in \%) in April 2005, for the same areas as Fig. 1. "Zone 1", "zone 2" and "zone 3" are located.

\subsection{Anthropogenic particles inventories}

\subsubsection{Sulphur particles and Black Carbon issues in East Asia}

We purposely limit the list of anthropogenic pollutants to only two major chemical families: (i) the main sulphur compounds, i.e. sulphur dioxide $\mathrm{SO}_{2}$ and its derivative products like gaseous $\mathrm{H}_{2} \mathrm{SO}_{4}$ and sulphate ions $\mathrm{SO}_{4}^{2-}$ (e.g. ammonium sulphates), all species thereafter referred to as "sulphates"; (ii) BC particles originated from combustions of various types. $\mathrm{BC}$ is seldom alone in troposphere, because Organic Carbon (OC) particles and Water Soluble Organic Carbon (WSOC) can also be found. Here, we focus on BC as an anthropogenic pollution tracer of Elemental Carbon (EC) type. 


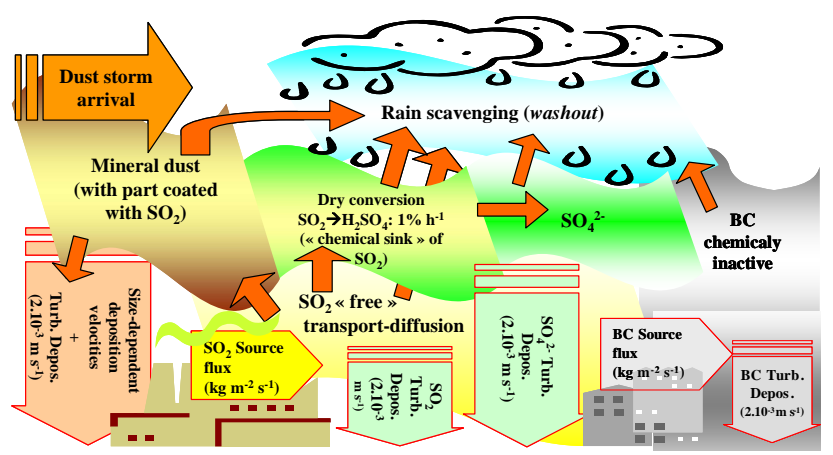

Fig. 3. Summary of the atmospheric processes undergone by sulphur compounds, mineral dust and BC accounted for in the simplified model over polluted areas.

Nitrogen oxides are known as major anthropogenic urban pollutants. However, in this study, we don't consider them because of their short lifetime in the free troposphere before being converted to $\mathrm{HNO}_{3}$ (Kunhikrishnan et al., 2004). Moreover, their contribution to the total AOT is weak compared to that of the absorbing $\mathrm{BC}$ and the scattering sulphates (Trijonis et al., 1990; Watson et al., 2001; Reddy et al., 2005).

$70 \%$ of Chinese power needs are provided by the combustion of poor quality coal (including up to $5 \%$ of sulphur), which generates considerable amounts of atmospheric $\mathrm{SO}_{2}$. For the year 2000, Chinese government statistics evaluate the country $\mathrm{SO}_{2}$ emissions up to $20 \mathrm{Mt}$, with $85 \%$ directly linked with coal combustion (Yang et al., 2002). Such pollution from sulphur severely impacts on public health and contributes to the acidic rain process, the consequences of which concern more than $30 \%$ of China. Japan is also concerned by sulphur pollution. The regional winds and the average meteorological conditions over the Korean peninsula and the Japanese archipelago explain why these two areas are so dramatically influenced by the continentally born pollutants (Hatakeyama et al., 1995).

The $\mathrm{BC}$ mass production is by far less important than the acidic pollutant mass emission. Thus, according to Wang (2004), we agree with a minor role of BC on the global temperature trend. On a regional scale, however, $\mathrm{BC}$ becomes a major actor of the local radiative budget and the local meteorological dynamics, as $\mathrm{BC}$ aerosol strongly absorbs the solar wavelengths. Consequently, $\mathrm{BC}$ increases the temperature of the atmospheric layer where it is present, and decreases the surface solar radiation at the same time. The heated air makes the surrounding air more unstable, creating a favourable ascending convection, in particular in China, leading to the formation of clouds which, in turn, are likely to produce precipitations on the strongly polluted areas. This situation is observed in China, but the opposite situation (the desaturation of the air layer and subsequent inhibition of cloud formation) can be observed on the Indian sub-continent (Minvielle, 2003).

\subsubsection{Model inventories for anthropogenic pollutants}

In former works, we have already used databases of $\mathrm{SO}_{2}$ and $\mathrm{BC}$ emissions, for example to make simulations related to the Indian Ocean Experiment (INDOEX) campaign (Minvielle et al., 2004a; 2004b). We again use these databases: for $\mathrm{SO}_{2}$, the Emission Database for Global Atmospheric Research (EDGAR) database available on http://www.mnp.nl/ edgar/model/edgarv32/acidifying/ (Olivier et al., 1996), and, for BC emissions, the Global Emissions Inventory Activity (GEIA) database available on http://www.geiacenter.org/ (with all references therein).

EDGAR database shows strong emissions of $\mathrm{SO}_{2}$ around central China (South of the studied area) as, for example, around Shangaii. A set of urban centres, roughly included inside a $(32 \mathrm{~N}-37 \mathrm{~N} ; 110 \mathrm{E}-118 \mathrm{E})$ area, give an annual average of $\mathrm{SO}_{2}$ emission higher than $0.7510^{-9} \mathrm{~kg} \mathrm{~m}^{-2} \mathrm{~s}^{-1}$. The area between Dalian and Shenyang, in the North of the Bohai Sea, a region of intense activity with industries and power plants, is estimated to be strongly emissive. In South Korea, Seoul is characterized by EDGAR as a very emissive place, just like the industrial port of Pusan in the South of the country.

According to the GEIA database, the main $\mathrm{BC}$ emissions are located close to the $\mathrm{SO}_{2}$ emitting zones: the principal urban centres and places of industrial activities, mining productions and power plants.

\subsection{A simple physico-chemical approach}

\subsubsection{Sulphur to sulphate conversion}

We suppose that sulphur emissions are $\mathrm{SO}_{2}$ gas emissions. After being injected within the RAMS first level, sulphur mass will be ruled according to the processes illustrated in Fig. 3. Only one chemical conversion is explicitly considered in our model: the conversion of "free" $\mathrm{SO}_{2}$ into $\mathrm{H}_{2} \mathrm{SO}_{4}$ (gas conversion). $\mathrm{H}_{2} \mathrm{SO}_{4}$ is then supposed to be quickly transformed into $\mathrm{SO}_{4}^{2-}$ (sulphate), because of the moisture present in the air. We use a dry conversion rate $\mathrm{SO}_{2} \rightarrow \mathrm{SO}_{4}^{2-}$ of $1 \%$ per hour, with

$d\left[\mathrm{SO}_{4}^{2-}\right]=-1.5 d\left[\mathrm{SO}_{2}\right]$

where $d\left[\mathrm{SO}_{2}\right]$ is the $\mathrm{SO}_{2}$ mass converted into sulphates at every time step. The coefficient of 1.5 accounts for the molar mass ratio.

Even if the major part of $\mathrm{SO}_{2}$ remains "free", we model the part which is coated (adsorbed) on mineral aerosol (Adams et al., 2005). As regards the mineral dust coated with $\mathrm{SO}_{2}$, we did not model, but we consider as very probable, the direct oxidation (if the atmospheric temperature is high enough) of $\mathrm{SO}_{2}$ into sulphate after its adsorption onto mineral particles. We just follow, for instance, the estimates of Dentener et al. (1996) who modelled large sulphate formation with mineral aerosol in the vicinity of the dust source regions, but we did not include such a process in our simplified tool. 


\subsubsection{Anthropogenic aerosols depositions}

The dry deposition of sulphur compounds (except for those captured by dust, §2.4.3) is ruled as recommended by Carmichael et al. (2001). Note that models are particularly sensitive to the direct ratio between the wet deposition of sulphates and precipitations on the one hand, and the estimate of the dry deposition of $\mathrm{SO}_{2}$ on the other hand. Concerning the turbulent deposition, Xu and Carmichael (1998) give dry deposition rates for $\mathrm{SO}_{2}$ and sulphates in Asia between less than $1 \mathrm{~mm} \mathrm{~s}^{-1}$ and $8 \mathrm{~mm} \mathrm{~s}^{-1}$. In this work, we choose a turbulent deposition velocity of $2 \mathrm{~mm} \mathrm{~s}^{-1}$ for $\mathrm{SO}_{2}$.

The interaction between aerosols and condensed water is limited to the washout processes in our numerical tool, because we estimate that rainout, if it could happen, has a marginal impact on the mass assessment of the free aerosols: we suppose that most of the aerosols captured by cloudy water will be released during the cloud evaporation period. Thus, we only consider the capture by rainwater. Observed rainfalls were weak during the modelled period. Nevertheless, we take the aerosol wet scavenging into account. We do not consider here the $\mathrm{SO}_{2} \rightarrow \mathrm{SO}_{4}^{2-}$ conversions by the aqueous pathway, following the conclusions of McNaughton et al. (2004) about the weak sulphates indirect radiative impact and their negligible direct effect in comparison to those of the primary aerosols and species which condense on them.

In our simulations, BC is accounted for by a single scalar, without any spectral distribution in size or mass. BC is prescribed according to a constant flow in the first level of the model, i.e. diluted on the first hundred meters above the surface. Once in suspension, unlike $\mathrm{SO}_{2}$, we do not consider $\mathrm{BC}$ captured by mineral dust. $\mathrm{BC}$ will thus be a chemically inert tracer compared to other pollutants. Its sinks are managed like those of the sulphur compounds. Uno et al. (2003) modelled the BC distribution during spring 2001 over China, Korea and Japan. Coupling their Chemical Weather Forecast System (CFORS) with the RAMS model, these authors supposed that BC particles were in a single mode (fine mode) and chose to be unaware of any process of gravitational or wet deposition like any process of chemical conversions. They simply used a turbulent deposition on the surface. We follow the same assumptions in this work. Uno et al. (2003) used a $1 \mathrm{~mm} \mathrm{~s}^{-1}$ turbulent velocity for BC deposition above land surface and $0.1 \mathrm{~mm} \mathrm{~s}^{-1}$ above ocean surface. According to previous sensitivity tests, we choose a single turbulent deposition velocity of $2 \mathrm{~mm} \mathrm{~s}^{-1}$.

\subsubsection{Sulphur mixing with dust}

Both chemistry sulphur products and mineral dust are modified by their mixing (Ma et al., 2004; Zhang et al., 2003). We also account for the $\mathrm{SO}_{2}$ gas captured by mineral particles over geographical areas polluted by anthropogenic emissions. The term "capture" will be understood as an internal mixture between the two species, whatever the mechanism.

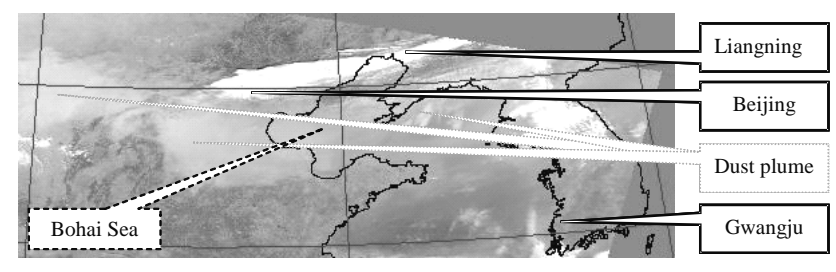

Fig. 4. MODIS image for 28 April 2005, 03:00 UTC, showing the mineral dust plume above the northeast of China. The cities of Beijing, Liangning, and Gwangju are located.

We do not consider the capture of BC by dust, nor the capture of secondary sulphates by dust. Moreover, as explained above, $\mathrm{SO}_{2} \rightarrow \mathrm{SO}_{4}^{2-}$ conversion on the dust surface is not modelled, but this phenomenon is assumed to occur quickly. Sulphate captured on dust particles is eliminated as the dust particles themselves are eliminated, i.e. by gravitational dry deposition and wet removal (\$2.2).

\section{Observational data}

\subsection{Remote sensing data}

\subsubsection{Satellite}

The Moderate Resolution Imaging Spectroradiometer (MODIS) Terra image of 28 April 2005 (Fig. 4) clearly shows a transport of yellow dust. This dust plume was observed over Japan on early May.

\subsubsection{Ground based data (visibility, AERONET, LIDAR)}

Using ground visibility data provided by the ECMWF observational database (Lasserre et al., 2005), we qualitatively observe, on 27 April 2005, a dust episode located towards (45N, 115E). At the beginning of 28 April 2005, the episode is located near the Southern point of the China-Mongolia border, an area inside (40-45N, 100-109E), area hereafter named "zone 1" (Fig. 2). On 29 April 2005, over the Korqin and Otindaq deserts, inside the (42-47N, 110-119E) area, hereafter noted "zone 2" (Fig. 2), a fall of visibility is observed due to dust transportation.

In order to quantitatively constrain this work, we use the AOT and the Angström Exponent (AE) provided by the spectrophotometers of the AERONET network (see Sect. 4.3). From 27 April 2005 to 2 May 2005, we will analyze the records at Dalanzadgad (43N, 104E), in Mongolia, located near the dust emissive zones. We also use, in China, AOT and $\mathrm{AE}$ measurements in Beijing and Liangning cities (41N, $122 \mathrm{E}$ ), the latter one also spelled Liaoyang, located approximately $500 \mathrm{~km}$ North-East of Beijing. Osaka (34N, 135E) is the only available AERONET site in Japan during the studied period. The AERONET site on Gwangju_K-JIST (35N, $126 \mathrm{E})$, also spelled Kwangju, provides data for South Korea. 


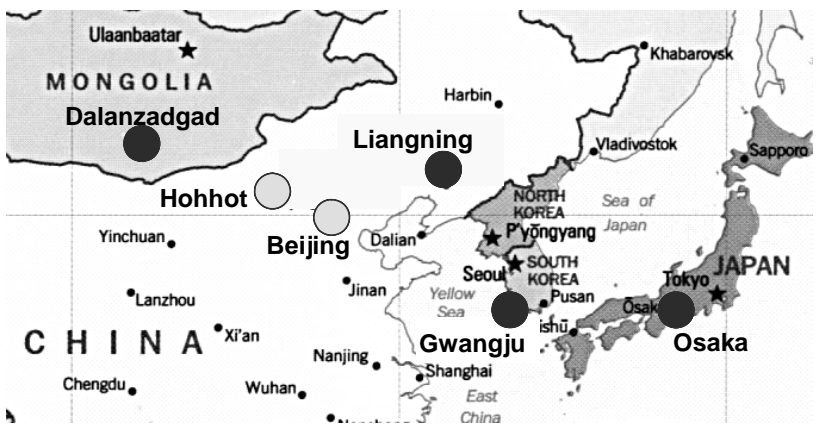

Fig. 5. Composite locating the AERONET sites used in this work, from 28 April 2005 to 2 May 2005. Hohhot city is located.

These various sites are located on Fig. 5 as well as Hohhot city (see next section).

In order to specifically analyse the modelled vertical structures of the aerosol plumes, we use the LIDAR backscattering/depolarisation images managed and provided by the National Institute for Environmental Studies (NIES, Ibaraki, Japan) according to the methodology of Shimizu et al. (2004).

3.2 In situ concentrations data and air quality index for Hohhot and Beijing cities

In situ $\mathrm{PM}_{10}$ measurements (hereafter referred to as in situ data), recorded by Chinese teams collaborating with the NIES, are used as surface $\mathrm{PM}_{10}$ concentrations data for Hohhot and Beijing. We focus on these two cities because they are representative of 2 distinct situations of aerosol mixing.

Hohhot (112E, 41N, $1100 \mathrm{~m}, 1.5 \mathrm{M}$ inhabitants) is located in Inner Mongolia, in the north-eastern loop of the Yellow River (or Huang He), approximately $450 \mathrm{~km}$ west of Beijing. This city is subjected to dust winds from the Gobi Deserts, from the Alxa plateau (also spelled Alashan) and from Mongolia. It is important to note that there are mountains close to the city (northern and north-western sides), whereas the other 2 cardinal directions open on to plains. Some shielding effect due to this relief on surface dust transport cannot be neglected. Our analyses at Hohhot will illustrate the aerosol mixing close to the mineral dust sources, but keeping in mind that Hohhot can be polluted by anthropogenic emissions, partly because of heavy industries being located in the western side of the city (e.g. steel-works and power station).

Beijing (116E, 39N, $15 \mathrm{M}$ inhabitants), the capital city of the People's Republic of China, is close to hills (1000 to $1500 \mathrm{~m}$ ) on the West, North and North-East directions. On the eastern aspect, the city opens on a large plain going gradually down to the Bohai Sea. We analyze the results in this city as being especially representative of the aerosols of interest: mineral dust coming from the continental deserts and the anthropogenic pollutants emitted by the city itself and the surrounding towns.

As available surface database, we also use - for these two Chinese cities - the estimates of the Air Pollution Index (API) provided by the State Environmental Protection Agency (SEPA), which is in charge to build a daily followup of the urban air quality in 80 cities (http://www.sepa.gov. cn/english/air_s.php3). An API daily value gives information about the most concentrated pollutant of the day. In Hohhot and Beijing cities, during the studied period, the prevailing pollutant is always indicated as " $\mathrm{PM}_{10}$ ", which means that pollution was controlled by particulate matter, and thus can include mineral dust. In case of prevailing pollution by gas, the API would be either $\mathrm{SO}_{2}$ or $\mathrm{NO}_{\mathrm{x}}$, but that case never happened during the studied period.

Using the conversion tables of daily API into daily average $\mathrm{PM}_{10}$ concentrations, which is valid for 6 successive linear intervals limited, by construction, between a minimum of $50 \mu \mathrm{g} \mathrm{m}^{-3}$ and a maximum $600 \mu \mathrm{g} \mathrm{m}^{-3}$ for $\mathrm{PM}_{10}$, we find a continuous easy-to-use conversion law by polynomial regression:

$$
\begin{aligned}
& \mathrm{PM}_{10}\left(\mu \mathrm{g} \cdot \mathrm{m}^{-3}\right)=8 \cdot 10^{-6}(\mathrm{API})^{3}-87 \cdot 10^{-3}(\mathrm{API})^{2} \\
& +36706(\mathrm{API})-12127\left(R^{2}=0.9968\right)
\end{aligned}
$$

Some authors (Li et al., 2003; Guo et al., 2004; Han et al., 2004) consider - as we do - API as an interesting dust episode indicator, as in Beijing (Zhang et al., 2003b), and use API to infer the concentrations of various specific species of aerosols. As it is difficult to know what is exactly chemically meant in the "PM 10 " mass load, and as API are only daily averages, we will not interpret them more accurately than a rough order of magnitude for particles smaller than $10 \mu \mathrm{m}$ (in diameter), as far as these particles do not exceed actually $600 \mu \mathrm{g} \mathrm{m}^{-3}$ because the corresponding API are not defined beyond (this value of $600 \mu \mathrm{g} \mathrm{m}^{-3}$ is a "saturation" maximum value).

\section{Results and discussions}

\subsection{General overview}

This section gives the model results for pollutants, but without any comparison with observational data (a detailed discussion of this issue, including further references to previous work on this subject and giving orders of magnitudes, is available in the ACPD version of this paper; Lasserre et al., 2007).

\subsubsection{Modelled dust flux budget}

The results of dust emissions are summarized in Table 1, which presents the fluxes simulated over the 3 areas defined before (Fig. 2): zone 1 (the South of the Gobi desert, remote from the shoreline), zone 2 (the south-east of the Gobi 
Table 1. Magnitudes of mineral dust mass production, inside zone 1, zone 2 and zone 3, from 27 April 2005, 00:00 UTC to 2 May 2005, 00:00 UTC.

\begin{tabular}{|c|c|c|c|c|c|}
\hline Zone & $\begin{array}{l}\text { Geographic } \\
\text { coordinates }\end{array}$ & $\begin{array}{l}\text { Total mass } \\
\text { produced } \\
\text { during } 5 \text { days } \\
(\mathrm{Mt})\end{array}$ & $\begin{array}{l}\text { Maximum } \\
\text { mass produced } \\
\text { during } 3 \mathrm{~h} \\
(\mathrm{Mt})\end{array}$ & $\begin{array}{l}\text { Average mass } \\
\text { produced } \\
\text { during } 3 \mathrm{~h} \\
(\mathrm{Mt})\end{array}$ & $\begin{array}{l}\text { Standard deviation } \\
\text { of the averaged } \\
\text { mass produced } \\
\text { during } 3 \mathrm{~h} \\
(\mathrm{Mt})\end{array}$ \\
\hline 1 & $(40-45 \mathrm{~N}, 100-109 \mathrm{E})$ & 1.27 & $\begin{array}{l}0.259 \\
(27,06: 00 \text { UTC })\end{array}$ & 0.031 & 0.051 \\
\hline 2 & $(42-47 \mathrm{~N}, 110-119 \mathrm{E})$ & 1.20 & $\begin{array}{l}0.090 \\
(29,03: 00 \text { UTC })\end{array}$ & 0.029 & 0.023 \\
\hline 3 & (38-50N, 94-119E) & 5.50 & $\begin{array}{l}0.456 \\
(27,06: 00 \text { UTC) }\end{array}$ & 0.134 & 0.111 \\
\hline
\end{tabular}

desert) and zone 3 (the overall Gobi desert, which roughly covers the whole dust source areas). Note that the relative anticyclonic situation over Taklamakan prevents any intense dust uptake from this desert during the period under study. Zones 1 and 2 are approximately of the same size (about $440000 \mathrm{~km}^{2}$ ). Table 1 presents the local maximum uptake for every $3 \mathrm{~h}$-interval modelled within each zone. The detailed results (not shown) highlight the extreme variability of real-time dust emissions. The variability is shown by the standard deviations which are of the same order of magnitude as the average value itself. The modelled values agree with literature data (summarized in Lasserre et al., 2005).

\subsubsection{Modelled surface plumes of anthropogenic and dust particles}

Figures 6 and 7 give an overview of the modelled surface plumes of anthropogenic and dust aerosols at 00:00 UTC ( 08:00 LT), from 27 April 2005 to 2 May 2005.

Both $\mathrm{BC}$ and $\mathrm{SO}_{2}$ plumes are located along the shoreline from Shanghai to the Koreas and Japan Sea via Beijing, and gradually extends towards Japan.

During 1 and 2 May 2005, $\mathrm{SO}_{2}$ concentrations exceeding $40 \mu \mathrm{g} \mathrm{m}^{-3}$ are modelled over the Eastern China Sea and South Japan while BC concentrations higher than $2 \mu \mathrm{g} \mathrm{m}^{-3}$ are to be found. It can be noted that the extreme $\mathrm{SO}_{2}$ concentrations (exceeding $300 \mu \mathrm{g} \mathrm{m}^{-3}$ ) are modelled only over some few places (close to Shanghai city or Seoul, for instance). Such values are sometimes observed in Asia, but are not typical features of the whole area, and the modelled values are often less than $200 \mu \mathrm{g} \mathrm{m}^{-3}$. Maximum BC modelled values are about $40-50 \mu \mathrm{g} \mathrm{m}^{-3}$. Those maxima are consistent with literature data. Sulphate concentrations (figure not shown) are widespread on the whole marine and coastal domain with a maximum about $5 \mu \mathrm{g} \mathrm{m}^{-3}$ in the North of Japan from 29 April 2005. Over the continent itself, peaks of concentrations towards Shanghai and Seoul are modelled, being certainly overestimated $\left(70-80 \mu \mathrm{g} \mathrm{m}^{-3}\right.$ ), but with a very sharp gradient around these extremely localized areas. Most of the sulphate concentrations are lower than $30-40 \mu \mathrm{g} \mathrm{m}^{-3}$, in agreement with the average values of Wang et al. (2006).

Modelled surface dust plume patterns (red curves, Figs. 6 and 7) highlight the contrasted origins of desert dust particles and pollutants, along with the role of wind in the aeolian emission process. The intermittency is therefore a common rule for desert dust, but not for anthropogenic pollutants. From these figures, it appears that the mixing zones of anthropogenic and mineral pollutants are of limited extent because the anthropogenic pollutants are on the East and South-East of the modelled area when the mineral dust plume extends from the centre to the East and South-East of the area. From 1 May 2005, the mineral dust plume seems to blow the anthropogenic pollutants already present in front of it. Behind the dust front, when the dusty air mass lies above the sources of pollution, it is permanently resupplied with the local anthropogenic pollutants, which favours some vertical mixing (and $\mathrm{SO}_{2}$ uptake onto dust particle as explained in the next section). However, as a general rule, the different aerosol species are modelled in separate plumes. The mineral dust coming from the North of the country seems to be confined for several days in the post-frontal air mass whereas the anthropogenic pollutants are found in the pre-frontal boundary layer. The mixing - mineral/anthropogenic - can take place within the interface of these air masses or through a slow diffusion process in a calmer air, as it seems to happen on 2 May 2005.

\subsubsection{Captures of $\mathrm{SO}_{2}$ by mineral dust}

Figure $8 \mathrm{a}$ and $\mathrm{b}$ respectively show the horizontal surface and the vertical zonal cross-section of the modelled dust plumes, along with $\mathrm{SO}_{2}$ captured by dust on 1 May 2005, 00:00 UTC (08:00 LT). The area of captured $\mathrm{SO}_{2}$ extends to the South and to the East and follows the front of the mineral dust plume. On 28 April 2005, 00:00 UTC (model result not shown), desert dust arrives in the area already polluted by 


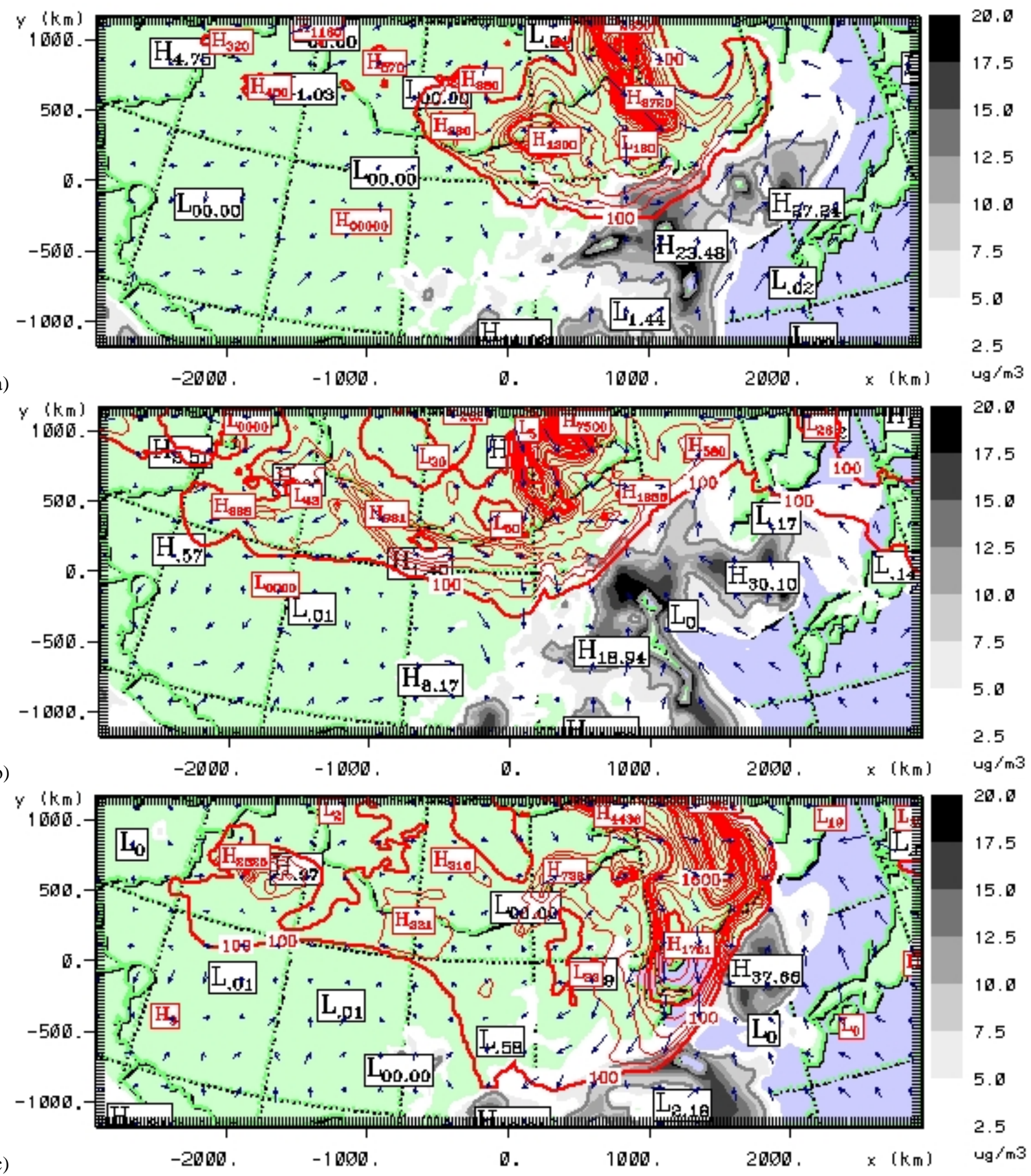

Fig. 6. Modelled surface BC concentrations (in $\mu \mathrm{g} \mathrm{m}^{-3}$, grey-coloured contours and black labels: $\mathrm{H}$ stands for maximum; $\mathrm{L}$ for minimum), and modelled surface dust concentrations (in $\mu \mathrm{g} \mathrm{m}^{-3}$, red-coloured contours and labels) at 00:00 UTC (08:00 LT). Blue arrows represent surface winds (a. u.): Results on 28 April (a), 30 April (b) and 1 May (c), 2005.

$\mathrm{SO}_{2}$ over the Bohai Sea. We find a maximum of $11 \mu \mathrm{g} \mathrm{m}^{-3}$ in $\mathrm{SO}_{2}$ captured by dust at surface level, and this value increases during the following days. On 29 April 2005, both dust and free $\mathrm{SO}_{2}$ surface plumes are more mixed and the overlapping zone shows a $13 \mu \mathrm{g} \mathrm{m}^{-3}$ maximum of captured
$\mathrm{SO}_{2}$ above the Bohai Sea. The model gives $44 \mu \mathrm{g} \mathrm{m}^{-3}$ on the west shore of South Korea while it is less than $4.4 \mu \mathrm{g} \mathrm{m}^{-3}$ over the Japan Sea, where, at the same time, the "clean" mineral dust concentration does not exceed $200 \mu \mathrm{g} \mathrm{m}^{-3}$. The simulation shows a notable dust emission starting from the 


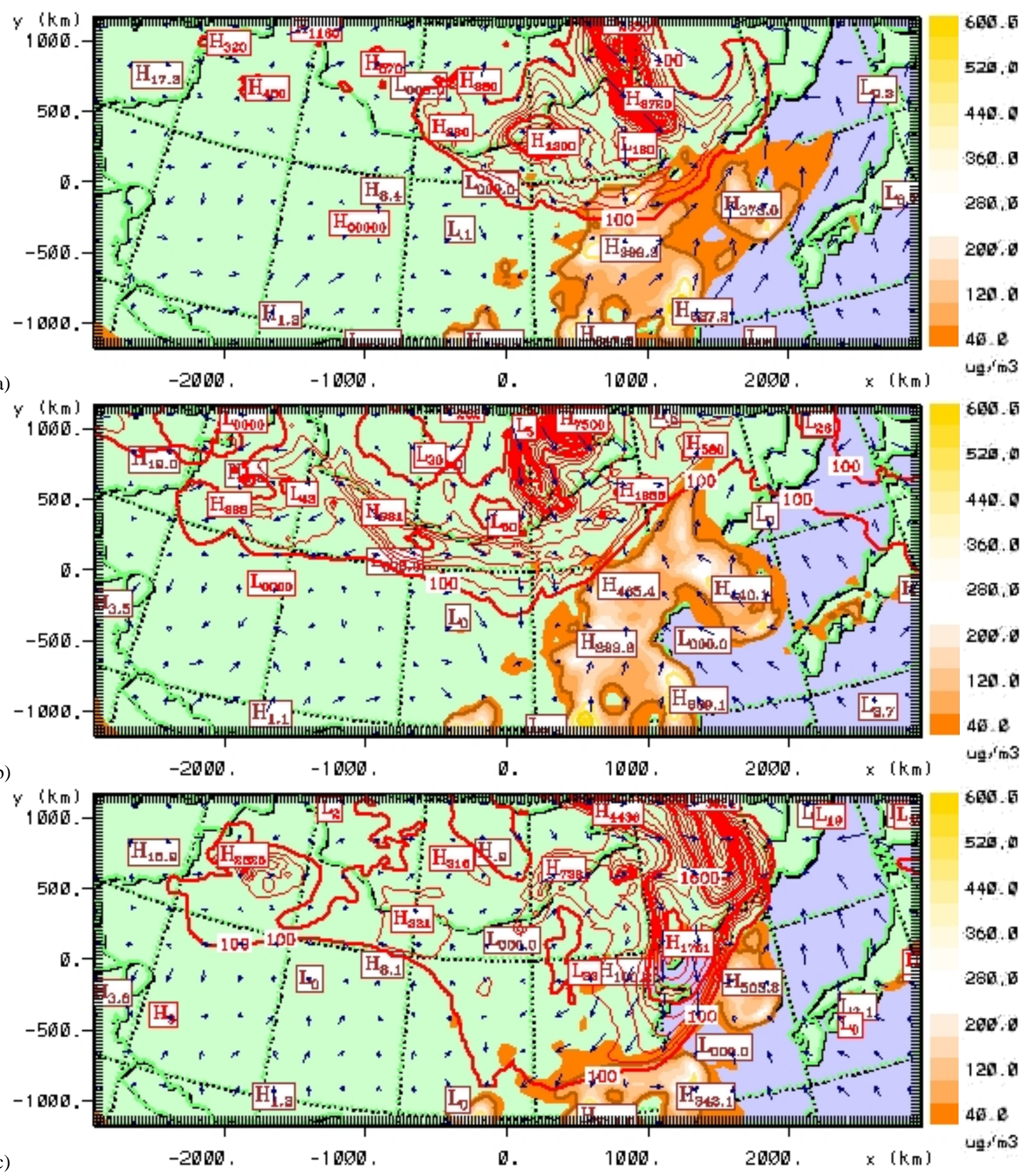

Fig. 7. Modelled surface $\mathrm{SO}_{2}$ concentrations (in $\mu \mathrm{g} \mathrm{m}^{-3}$, orange-coloured contours and brown labels: $\mathrm{H}$ stands for maximum; L for minimum), and modelled surface mineral dust concentrations (in $\mu \mathrm{g} \mathrm{m}^{-3}$, red-coloured contours and labels) at 00:00 UTC (08:00 LT). Blue arrows represent surface winds (a. u.): Results on 28 April (a), 30 April (b) and 1 May (7), 2005.

end of 30 April 2005. On 1 May 2005 (Fig. 8a), as the horizontal gradients of surface concentrations at the South and East of dust front are very important, the mixing only takes place inside a bow-shaped area of approximately $200 \mathrm{~km}$ in extent. On 2 May 2005, the intensity of wind decreases in the South and dust spreads over the most polluted zone, so that an increasing fraction of $\mathrm{SO}_{2}$ is captured by mineral particles. Maximum surface values from the South to the North of the China Sea shoreline range from $93 \mu \mathrm{g} \mathrm{m}^{-3}$ (Shangaï) to $41 \mu \mathrm{g} \mathrm{m}^{-3}$ (West of South Korea). 


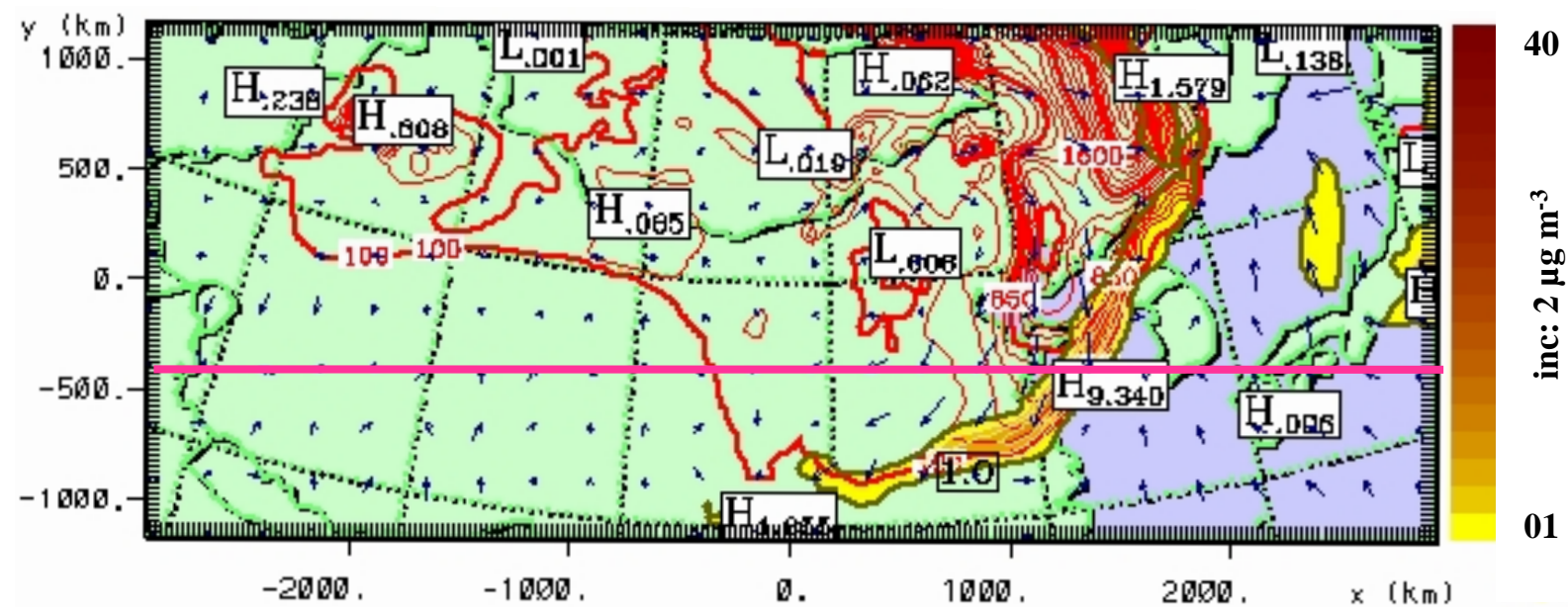

Fig. 8a. Modelled surface "captured" $\mathrm{SO}_{2}$ concentrations (in $\mu \mathrm{g} \mathrm{m}^{-3}$, yellow-coloured contours and black labels: $\mathrm{H}$ stands for maximum; $\mathrm{L}$ for minimum), and modelled surface mineral dust concentrations (in $\mu \mathrm{g} \mathrm{m}^{-3}$, red-coloured contours and labels) on $1 \mathrm{May} 2005$, 00:00 UTC (08:00 LT). Blue arrows represent surface winds (a. u.).

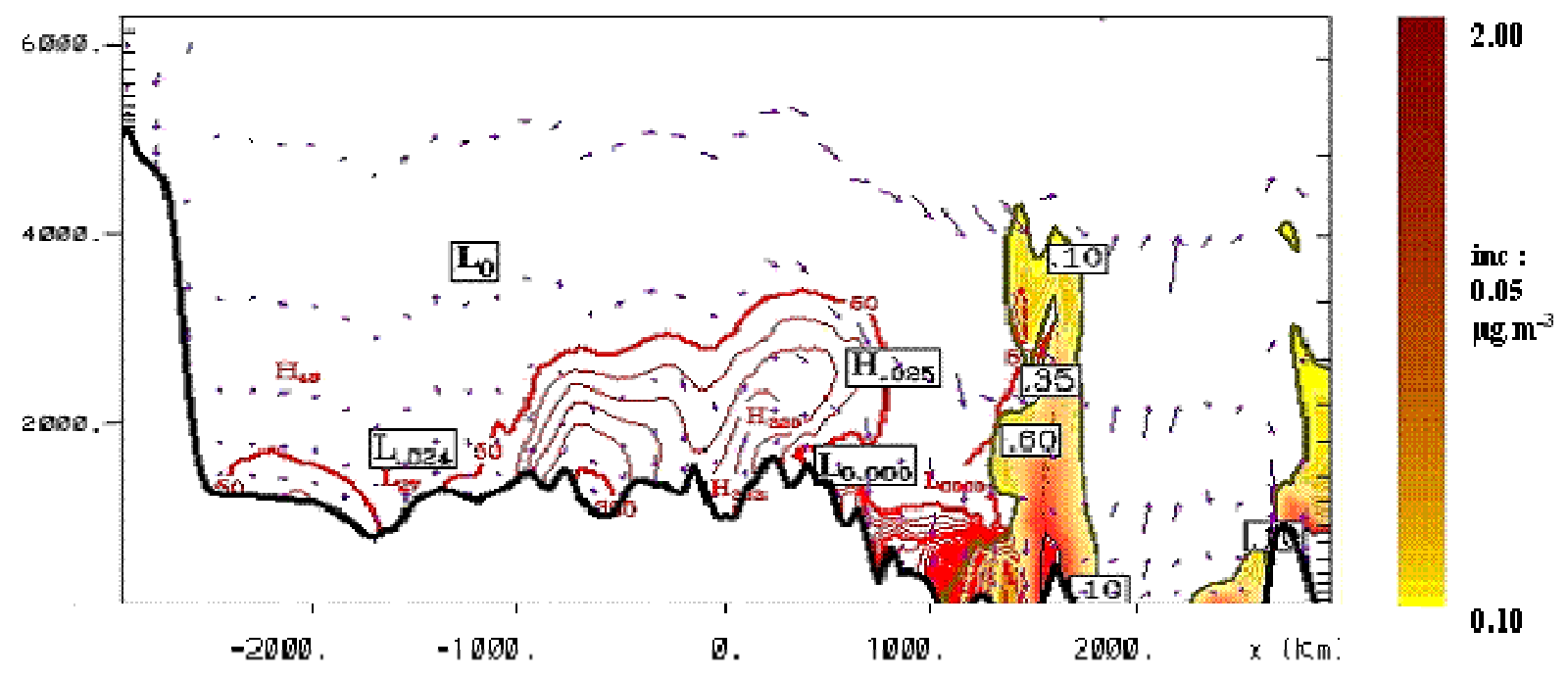

Fig. 8b. Vertical cross-section of the modelled "captured" $\mathrm{SO}_{2}$ concentrations (in $\mu \mathrm{g} \mathrm{m}^{-3}$, yellow-coloured contours and black labels), and of the modelled mineral dust concentrations (in $\mu \mathrm{g} \mathrm{m}^{-3}$, red-coloured contours and labels: $\mathrm{H}$ stands for maximum; $\mathrm{L}$ for minimum) along the pink line represented on Fig. 1 on 1 May 2005, 00:00 UTC (08:00 LT). Altitudes are in meters and Blue arrows represent winds (a. u.).

Figure $8 \mathrm{~b}$ displays a vertical zonal cross-section of the plumes sufficiently at the North of the simulated zone (pink line, Fig. 8a) so that the modelled vertical profiles are representative of transport likely to pollute Japan and illustrate a regional situation of quasi permanent pollution. Figure $8 \mathrm{~b}$ superimposes the $\mathrm{SO}_{2}$ concentrations captured by mineral dust and isolines of mineral dust concentrations themselves. The 3-h sequence shows that, after the westerly dust front income, the mixing between $\mathrm{SO}_{2}$ and mineral plumes (delineated by the minimum $50 \mu \mathrm{g} \mathrm{m}^{-3}$ red isoline) always occurs between the surface and $2000 \mathrm{~m}$ agl on 29 and 30 April 2005, and to approximately $4000 \mathrm{~m}$ on 1 May 2005, when captured
$\mathrm{SO}_{2}$ concentrations are about $0.1 \mu \mathrm{g} \mathrm{m}^{-3}$. The captured $\mathrm{SO}_{2}$ concentrations decrease very quickly with altitude, and more quickly, as a whole, than the concentrations of dust and free $\mathrm{SO}_{2}$ do. In the lower layers, the maxima of captured $\mathrm{SO}_{2}$ concentrations are found especially from the North of the Bohai Sea to Japan. Over the Japan Sea, the modelled surface concentrations are less than $7 \mu \mathrm{g} \mathrm{m}^{-3}$. The maxima in the whole of the vertical section are (every day at 00:00 UTC) as follows: $7.2 \mu \mathrm{g} \mathrm{m}^{-3}$ for 28 April 2005, $4.3 \mu \mathrm{g} \mathrm{m}^{-3}$ for 29 April 2005, $4.3 \mu \mathrm{g} \mathrm{m}^{-3}$ for 30 April 2005, $4.8 \mu \mathrm{g} \mathrm{m}^{-3}$ for 1 May 2005 and $9.1 \mu \mathrm{g} \mathrm{m}^{-3}$ for 2 May 2005 . 


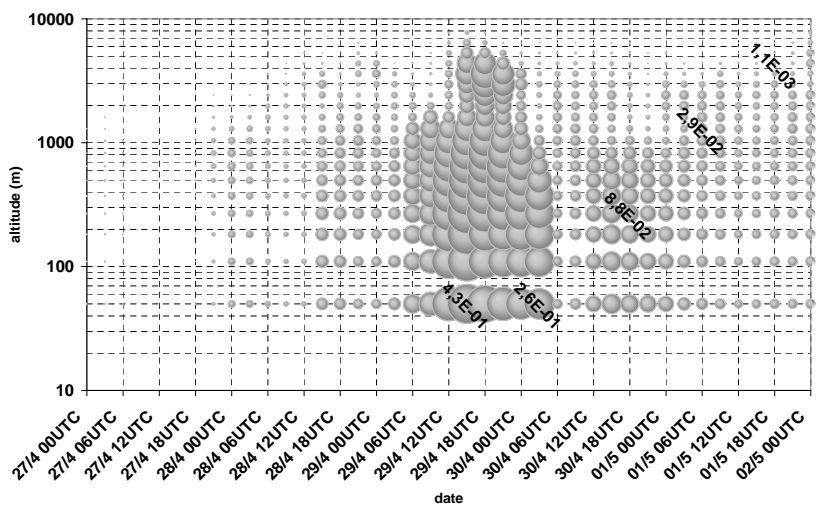

Fig. 9. Symbolic intercomparison of the "captured" $\mathrm{SO}_{2}$ concentrations (grey spheres): time series (UTC) of the vertical distributions (altitudes: logarithmic scale) over Beijing.

In order to qualitatively illustrate the heterogeneous spatio-temporal feature of the $\mathrm{SO}_{2}$ capture, Fig. 9 displays the chronological evolution of the vertical distribution of $\mathrm{SO}_{2}$ captured by dust above Beijing. The captured $\mathrm{SO}_{2}$ concentrations (symbolized by full circular surfaces, with size proportional to the captured $\mathrm{SO}_{2}$ ) range from $10^{-3}$ to $0.5 \mu \mathrm{g} \mathrm{m}^{-3}$ (magnitudes are specified in some points). This figure gives an idea of the relative intensities of the captures in time and altitude.

It is interesting to note that on 28 April 2005, when surface dust concentrations increase, the capture of $\mathrm{SO}_{2}$ does not immediately increase and shows a rather homogeneous vertical profile between $100 \mathrm{~m}$ and $1000 \mathrm{~m}$ a.g.l. The highest concentrations, located under $2000 \mathrm{~m}$ agl, happen after the maximum in surface dust concentrations of 28 April 2005. The mixing process occurs in a deepening layer, which reaches 4000-5000 m on late 29 April 2005 (UTC). From 30 April 2005 , the mixing process is interrupted due to a lack of dust.

\subsection{Model validation of mineral dust over Hohhot and Beijing}

We now discuss the model results as compared with the observational data directly related to the studied case.

\subsubsection{Hohhot surface dust concentrations}

Figure 10a presents the time series of the surface mineral dust concentrations modelled at Hohhot. The concentrations observed in situ and the daily $\mathrm{PM}_{10}$ concentrations deduced from the API data are superimposed. On the same figure, as further discussed, the modelled mineral dust column load over Hohhot is also displayed. In Hohhot, in the afternoon of 27 April 2005, south-westerly wind blew between 3 to $14 \mathrm{~m} \mathrm{~s}^{-1}$ in gusts and turned North from 23:00 LT with a fall in visibility to $3 \mathrm{~km}$ before rising to $7 \mathrm{~km}$ after midnight

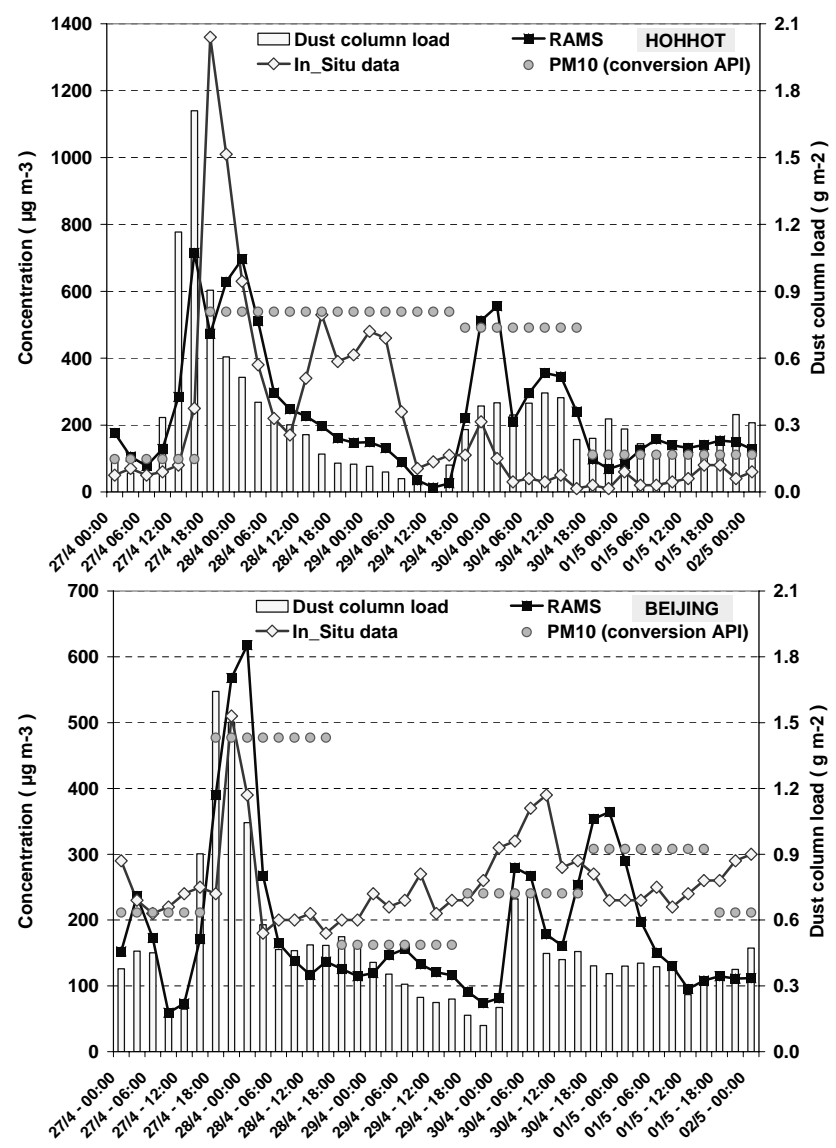

Fig. 10. Time series of the surface mineral dust concentrations (in $\mu \mathrm{g} \mathrm{m}^{-3}$ ) and of the vertical integrated column load (in $\mathrm{g} \mathrm{m}^{-2}$ ) over Hohhot (a) and Beijing (b): modelled concentrations (black squares); in situ observed concentrations (diamonds); $\mathrm{PM}_{10}$ concentrations from API data (grey circles) and modelled column loads (bar charts).

(see observations on http://www.wunderground.com/history/ airport/ZBHH/2005/4/27/DailyHistory.html).

An intense dust episode is clearly modelled in the morning of 28 April 2005 in local time (end of 27 April 2005, UTC). The time series of surface concentrations for 27 and 28 April 2005 presents a phase delay of a few hours as compared to the column loads. Thus, the model calculates a transport of dust occurring in a differentiated way according to altitude. The maximum surface concentration modelled for 30 April 2005 is synchronized with those of the dust column loads: this second dust front was close to the surface.

Modelled dust concentrations agree with in situ data and API data for the main tendencies, but some discrepancies are found. The correlation coefficient between in situ data and model products is 0.49 , which is significant with a real-time simulation using a $3 \mathrm{~h}$ output frequency. Model results underestimate the observations for the main event of 28-29 April 2005 , according to local observations. The $\mathrm{PM}_{10}$ values from API of 28 and 29 April 2005 tend towards the maximum 

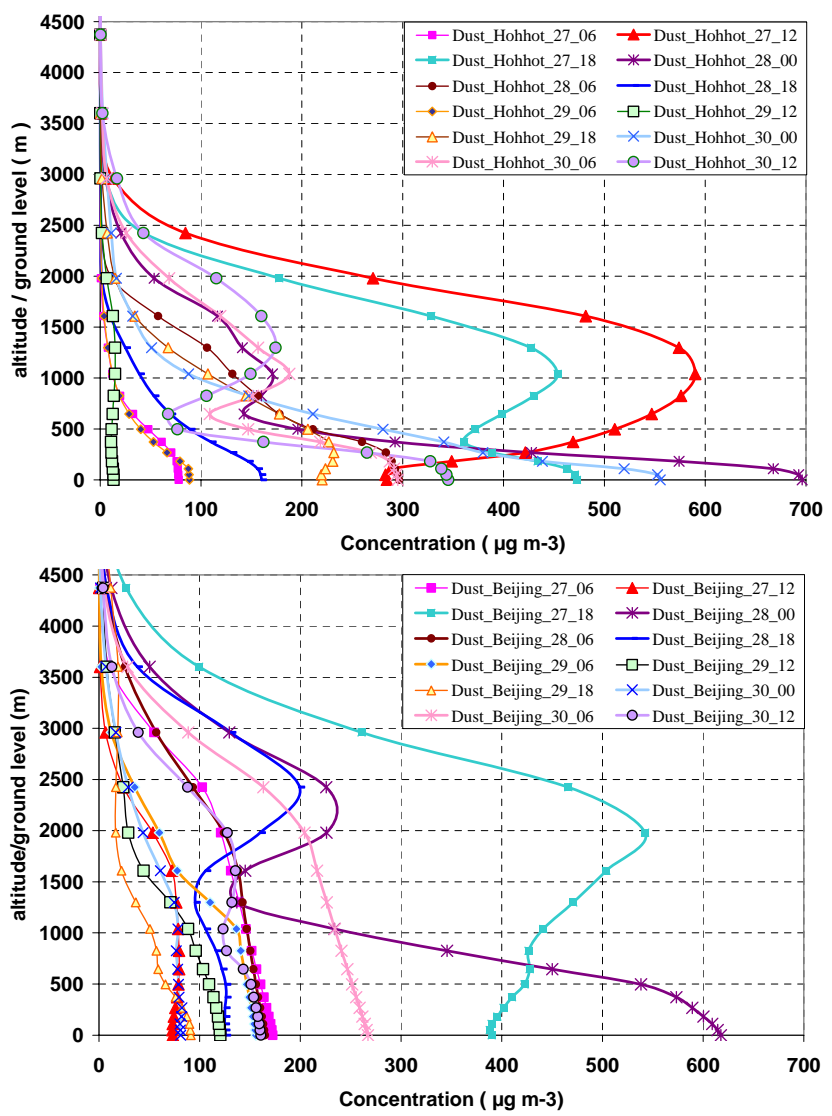

Fig. 11. Vertical profiles of the modelled dust concentrations (in $\mu \mathrm{g} \mathrm{m}^{-3}$ ) between the surface and $4500 \mathrm{~m}$ above Hohhot (a) and Beijing (b) from 27 April 2005, 06:00 UTC to 30 April 2005, 12:00 UTC.

possible values of API. These observed $\mathrm{PM}_{10}$ values must thus be considered as estimates of the lower limits of the actual averaged concentrations for these two days. For the second dust event, on 30 April 2005, we note, contrary to the previous days, a model overestimation as compared to in situ measurements, but a very good agreement with the estimate of the interpolated $\mathrm{PM}_{10}$. Eventually, all 3 sets of values (calculations of the model, in situ measurements and $\mathrm{PM}_{10}$ deduced from API) closely converge at the beginning of May, showing a decrease in surface dust transport with values of about $100 \mu \mathrm{g} \mathrm{m}^{-3}$.

Model results in Hohhot are - of course - not exactly in agreement with the in situ measurements, but they agree with the temporal evolution and tendencies of the surface observations as well as typical contemporary models. Thus, we now examine how the numerical tool models the vertical profile of dust transport over Hohhot.

\subsubsection{Hohhot dust vertical profiles}

Figure 11a shows the vertical profiles of mineral dust concentrations every $6 \mathrm{~h}$, on the first 4500 m a.g.l. (16 first RAMS levels) above Hohhot. The modelled profile on 27 April 2005, 12:00 UTC, shows a maximum concentration of approximately $600 \mu \mathrm{g} \mathrm{m}^{-3}$ around $1000 \mathrm{~m}$, which corroborates the assumption of a sandstorm having flown over Hohhot in altitude before the dust transported to the surface does arrive on the city itself (which is probably due to an orographic effect). On late 27 April 2005, the ground concentration is twice less than the $1000 \mathrm{~m}$ value, but, six hours later, the profile shows an inversion. This ended on 28 April 2005 at 00:00 UTC when the concentrations decrease in a quasimonotonous way with altitude (about $700 \mu \mathrm{g} \mathrm{m}^{-3}$ on surface level and $170 \mu \mathrm{g} \mathrm{m}^{-3}$ at $1000 \mathrm{~m}$ ). On 30 April 2005, 00:00 UTC (08:00 LT), the second dust event is initially close to the ground, then the profile bends and a maximum appears between $1000 \mathrm{~m}$ and $2000 \mathrm{~m} 12 \mathrm{~h}$ later. As this dust event originates from the North, we again hypothesize the orographical effects as regards the abrupt variations in the shapes of the dust vertical profile.

Figure 12a presents the LIDAR normalised Backscattering Intensities (hereafter referred to as $\mathrm{BI}$ ) and Depolarization Ratios (DR), with a $532 \mathrm{~nm}$ wavelength, $3000 \mathrm{~m}$ above Hohhot. On 27 April 2005, 06:00 UTC, the atmosphere does not contain any depolarizing aerosols, i.e. it mainly contains anthropogenic pollutants. The first event (27 April 2005) exhibits a vertical extension higher than $2000 \mathrm{~m}$, similar to model results (with a few hours of delay). Then, LIDAR products show a transition with "mixed" aerosols, with a vertical extension exceeding $2500 \mathrm{~m}$ a.g.l. Just after 12:00 UTC, also on 27 April 2005, LIDAR data show a substantial decrease in the BI level, limited to the first hundred meters: it indicates an aerosol plume at very low altitude, while the DR abruptly increase and reach more than $30 \%$ between the ground and $1000 \mathrm{~m}$, which strongly suggests the presence of mineral aerosols (depolarizing particles). On 29 April 2005, $\mathrm{BI}$ and DR reductions are observed as well, indicating a less polluted day. On 30 April 2005, around 00:00 UTC, the increase of DR suggests new mineral particles, also retrieved by the model. It is more difficult to interpret the form of this LIDAR observation, but it exhibits a vertical extension again exceeding $2000 \mathrm{~m}$, which corroborates our profiles' calculations around 30 April 2005, 12:00 UTC (Fig. 11a).

As a whole, our simulations at Hohhot roughly agree with the overall evolution of the LIDAR backscattering shape.

\subsubsection{Beijing surface dust concentrations}

Two sandstorm events occurred between 27 April 2005 and 2 May 2005 over Beijing. The first one (27 and 28 April 2005) is related to the intense dust transport already mentioned at Hohhot. The second episode was observed at Beijing rather than at Hohhot. Figure 10b presents the time series of the in 
situ and simulated surface concentrations and the estimates of the daily $\mathrm{PM}_{10}$ concentrations derived from the API. For the first dust event, in situ measurements at 21:00 UTC on 27 April 2005 (i.e. approximately 28 April 2005, 05:00 LT) is $510 \mu \mathrm{g} \mathrm{m}^{-3}$, which closely agrees with model values: maximum modelled ground concentrations range from 570 to $620 \mu \mathrm{g} \mathrm{m}^{-3}$. For 28 April 2005, the averaged $\mathrm{PM}_{10}$ from API is estimated at $480 \mu \mathrm{g} \mathrm{m}^{-3}$. The duration of the episode is approximately $9-12 \mathrm{~h}$ according to our calculations, which correctly includes the peak observed in in situ measurements.

After this dust event and until 30 April 2005, Beijing is not concerned by substantial dust transport, but always remains with a non negligible background pollution content (see on 29 April 2005: in situ data are often higher than $200 \mu \mathrm{g} \mathrm{m}^{-3}$ and $\mathrm{PM}_{10}$ from API reach $160 \mu \mathrm{g} \mathrm{m}^{-3}$ ). Model results (i.e. desert dust component) present a rather satisfactory order of magnitude. The second dust event (30 April and 1 May 2005) is also modelled, with similar magnitude in dust concentrations (200-400 $\mu \mathrm{g} \mathrm{m}^{-3}$ ), in spite of some temporal model delay.

In Beijing, as far as it can be interpreted, the overall correlation coefficient is 0.56 between the results of $3 \mathrm{~h}$ real-time modelled surface concentrations and in situ data.

\subsubsection{Beijing dust vertical profiles}

The dust column loads are also shown on Fig. 10b. The two curves phase coincidence - ground concentrations data and column load - suggests that the dust events over Beijing were relatively homogeneous with altitude. According to Fig. 11b, on 27 April 2005, from 00:00 UTC to 06:00 UTC, dust concentrations look very homogeneous in the vertical (concentrations vary slowly from the surface to $2500 \mathrm{~m}$ ) ranging from $180 \mu \mathrm{g} \mathrm{m}^{-3}$ to $100 \mu \mathrm{g} \mathrm{m}^{-3}$. This first event is the forerunner of the most intense phenomenon that occurs $12 \mathrm{~h}$ later approximately, after a transition with a less polluted air. More complex profiles, showing high values in altitude (550 $\mu \mathrm{g} \mathrm{m}^{-3}$ around $2000 \mathrm{~m}$ on 27 April 2005, 18:00 UTC), are following. Initially in the form of a "shark nose" (18:00 UTC), the vertical dust profile evolves to form two layers: on the surface (maximum around $620 \mu \mathrm{g} \mathrm{m}^{-3}$ ), and between 2000 and $2500 \mathrm{~m}$ a.g.l., where the concentrations exceed $200 \mu \mathrm{g} \mathrm{m}^{-3}$, on 28 April 2005, 00:00 UTC. Lastly, the vertical profile of 30 April 2005 looks like the one of 27 April 2005, i.e. a rather homogeneous profile with concentrations higher than $200 \mu \mathrm{g} \mathrm{m}^{-3}$ from the surface to $2000 \mathrm{~m}$ agl.

Figure $12 \mathrm{~b}$ presents the LIDAR measurements (BI and DR) recorded at Beijing at the end of April 2005. These data are compared to our simulations of vertical dust profiles. LIDAR confirms the relatively homogeneous distribution between the surface and $1500 \mathrm{~m}$ for 27 April 2005. The intermediate DR $(\sim 10 \%-20 \%)$ reveals a mixture of anthropogenic and dust aerosols. From 27 April 2005, 18:00 UTC, i.e. early local morning of 28 April 2005, the BI suddenly in-
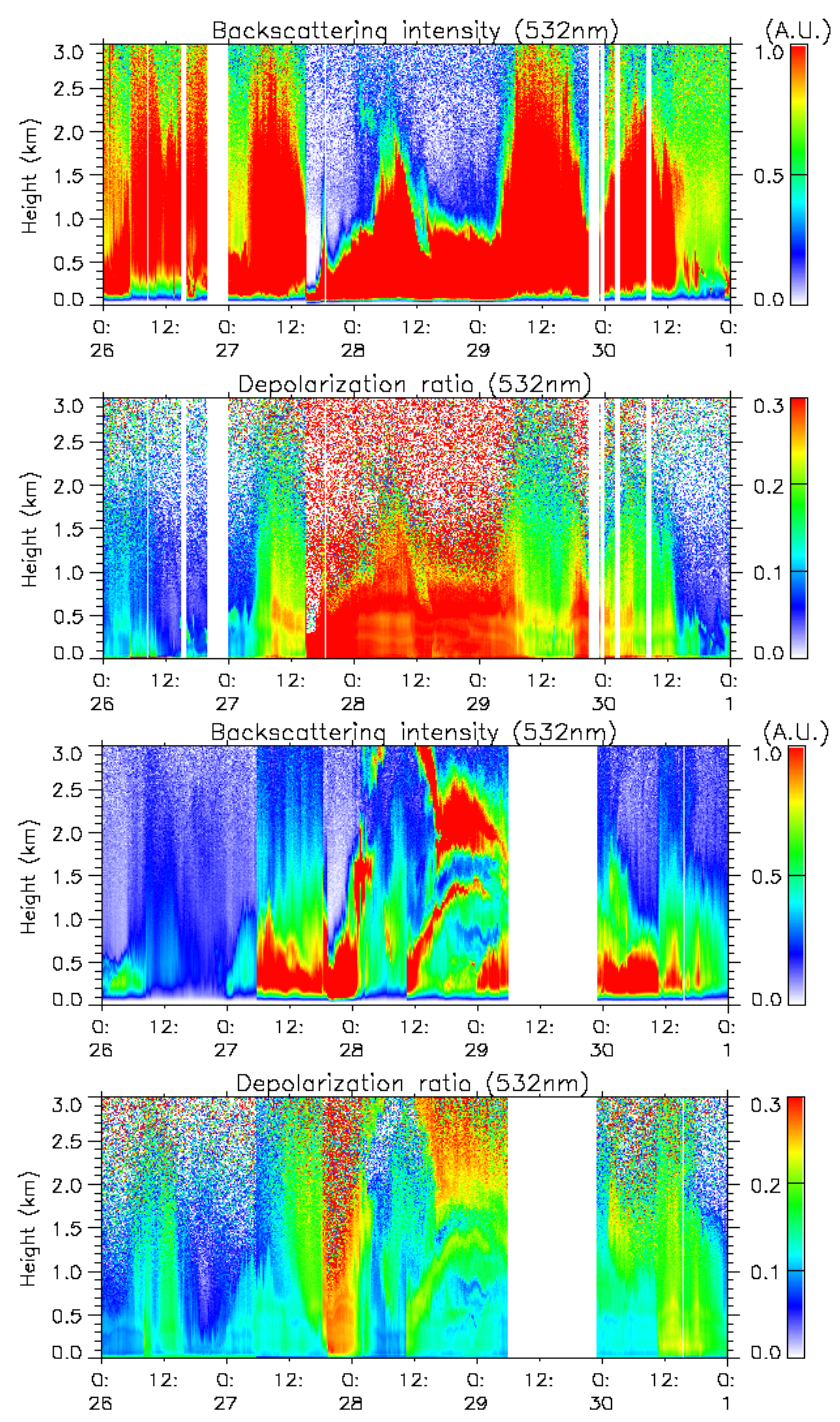

Fig. 12. Lidar measurements $(532 \mathrm{~nm})$ from 26 April 2005, 00:00 UTC to 1 May 2005, 00:00 UTC at Hohhot (upper group of two figures) and Beijing (lower group of two figures). For each group: - higher part: backscattering intensities (a. u.) - lower part: depolarisation ratio.

crease, showing the dust plume initially near the surface (the maximum height ranging between 500 and $1000 \mathrm{~m}$ ) as we model it for 28 April 2005, 00:00 UTC. During daytime, the BI exhibit two layers (0-1000 $\mathrm{m}$ and 2000-3000 m) whereas the DR strongly suggest a complex mixing of the shapes of the aerosols. The second event (30 April 2005) seems to be located between the surface and $1500 \mathrm{~m}$ a.g.l. DR show that this last event carries a lower mineral load than the event of 28 April 2005. As dust, if present, is much more concentrated than anthropogenic pollutants, our comparisons with $\mathrm{PM}_{10}$ observations concern the actual overall $\mathrm{PM}_{10}$ species versus the only modelled dust concentrations. The model gives concentrations close to the observed ones during the 
Table 2. Summary statistics of the modelled surface concentrations, from 27 April 2005, 00:00 UTC to 2 May 2005, 00:00 UTC, for Hohhot and Beijing.

\begin{tabular}{|c|c|c|c|c|c|c|c|c|}
\hline \multirow{2}{*}{$\begin{array}{l}\text { Volume } \\
\text { concentrations } \\
\text { Statistics }\left(\mu \mathrm{g} \mathrm{m}^{-3}\right)\end{array}$} & \multicolumn{4}{|c|}{ Hohhot } & \multicolumn{4}{|c|}{ Beijing } \\
\hline & Mineral dust & $\mathrm{SO}_{2}$ & $\mathrm{SO}_{4}^{2-}$ & $\mathrm{BC}$ & Mineral dust & $\mathrm{SO}_{2}$ & $\mathrm{SO}_{4}^{2-}$ & $\mathrm{BC}$ \\
\hline Average & 235 & 4.15 & 1.09 & 1.07 & 188 & 37.2 & 4.05 & 4.00 \\
\hline Standard deviation & 183 & 5.28 & 1.80 & 0.74 & 123 & 23.4 & 5.32 & 2.49 \\
\hline Minimum & 13 & 0.31 & 0.02 & 0.26 & 59 & 5.58 & 0.15 & 0.68 \\
\hline Maximum & 715 & 21.5 & 7.64 & 3.03 & 618 & 85.0 & 18.30 & 9.45 \\
\hline
\end{tabular}

dust storm episodes and concentrations slightly inferior to the $\mathrm{PM}_{10}$ observations when the dust event is lower, but present. In order to know the contributions of $\mathrm{BC}$ and sulphates which could be added to the dust one to partially complete the $\mathrm{PM}_{10}$ simulation, we added these values (see Table 2 for summary) to the dust values, and noticed that the simulated $\mathrm{PM}_{10}$ figures over Beijing were not significantly modified. More precisely, these modifications would be absolutely irrelevant according to the accuracy of the local observations as compared to the horizontal accuracy of the model.

As a conclusion to this part devoted to the results of the real-time modelling of mineral dust over Beijing, we estimate that they realistically show the qualitative and even quantitative aspects of the event that really occurred.

4.3 Optical signatures of anthropogenic and mineral aerosols

\subsubsection{Principles for the calculation of the Aerosol Optical Thickness}

The modelled $\mathrm{BC}, \mathrm{SO}_{2}$ and sulphates concentrations agree qualitatively well with the orders of magnitude of literature. Our simplified representation of the aerosols' cycle must be validated by kinds of easily accessible physical measurements. Quantitatively, as stated above, we choose to compare the aerosols simulations with radiometric data: Aerosol Optical Thicknesses $\tau$ (AOT) and Angström Exponent $\alpha$ (AE), both characteristic of the aerosols present in the atmosphere.

In order to estimate the observed AOT, we proceed as follows: each of the four types of studied aerosols (mineral dust, $\mathrm{BC}$, free $\mathrm{SO}_{4}^{2-}$ and $\mathrm{SO}_{4}^{2-}$ on dust resulting from the oxidation of the captured $\mathrm{SO}_{2}$ ) is allotted a specific extinction section $\sigma_{j \text { ext }}\left(\mathrm{m}^{2} \mathrm{~g}^{-1}\right)$. The specific extinction section $\sigma_{j \text { ext }}$ describes the specific absorbing and scattering aptitudes of the $j$-aerosol in a single physical variable. The main interest of $\sigma_{\text {jext }}$ consists in being easy to use, because it just needs to be multiplied by the vertical column load $C_{j}\left(\mathrm{~g} \mathrm{~m}^{-2}\right)$ of the $j$-aerosol to obtain the specific AOT for this $j$-aerosol specie:

$\tau_{j}=\sigma_{j \mathrm{ext}} \cdot C_{j}$
Of course, this method is made at the expense of a rigorous establishing of $\sigma_{\text {jext }}$. Details are given in the ACPD version of the present paper (Lasserre et al., 2007) and recall that the extinction coefficients are highly scattered (see the $\sigma_{\text {ext }}$ values table).

As regards $\mathrm{SO}_{2}$ captured by mineral dust, we no longer consider it as a gas, but as an aerosol, because, as explained above, we assume that it is quickly transformed into sulphate: we allot it with a $\sigma_{\text {sulphate/dext }}$ value equal to the one of the free sulphates.

The $\sigma_{\text {ext }}$ values were ruled as:

Sulphates:

Black Carbon:

Mineral dust:

$$
\begin{aligned}
& \sigma_{\mathrm{SO}_{4} \text { ext }}=8 \mathrm{~m}^{2} \mathrm{~g}^{-1} \\
& \sigma_{\mathrm{BC} \text { ext }}=12 \mathrm{~m}^{2} \mathrm{~g}^{-1} \\
& \sigma_{d \text { ext }}=1.2 \mathrm{~m}^{2} \mathrm{~g}^{-1}
\end{aligned}
$$

Sulphates on mineral dust: $\quad \sigma_{\text {sulphate } / d \text { ext }}=8 \mathrm{~m}^{2} \mathrm{~g}^{-1}$.

\subsubsection{Validation of modelled AOT with the AERONET AOT and AE data}

Every 3 h, from 27 April 2005 to 2 May 2005, 00:00 UTC, we display the AOT of the atmospheric columns according to the simple formula:

$\tau=\sum_{j=1}^{4} \sigma_{j \mathrm{ext}} \cdot C_{j}$

Inside the total modelled AOT, we especially model the distribution of the various $\operatorname{AOT}(j)$ related to each of the four aerosol species in order to estimate which one dominates the extinction in the solar domain. Lastly, the total modelled AOT are validated by comparison with the time series of the observed AOT and the $\mathrm{AE}$ data provided by the AERONET network of photometers, at five locations: Dalanzadgad (Mongolia), Beijing, Liangning (NE China), Gwangju (South Korea) and Osaka (Japan).

The AERONET AOT data are of three quality levels: 1.0, 1.5 and 2.0. As a major objective of our case study was to directly compare the $3 \mathrm{~h}$ - real-time model output with the instantaneous data on each measurement site, we knowingly decide to use the straight "rough" data of AOT of level 1.0. Indeed, levels 1.5 and 2.0 postprocessings tend to smooth 
the time variations of the AOT by removing some high values (which could be due to clouds, but also due to thick dust plumes). To some extent, these 1.5 and 2.0 levels prevent from really taking into account the transport of the Asian aerosols "in real-time".

For the sake of clarity, we only use the AOT at $500 \mathrm{~nm}$ (Dalanzadgad, Liangning) or 675 nm (Beijing, Gwangju, Osaka) at each time step. However, in order to give more information about the nature of the aerosol via its spectral signature, we also plot the AE, defined by Angström (1964):

$\alpha=\ln \left(\frac{\tau_{\lambda_{1}}}{\tau_{\lambda_{2}}}\right) / \ln \left(\frac{\lambda_{2}}{\lambda_{1}}\right)$

where $\tau_{\lambda_{1}}$ (resp. $\tau_{\lambda_{2}}$ ) is the AOT corresponding to the wavelength $\lambda_{1}$ (resp. $\lambda_{2}$ ). We used AE data with $\lambda_{1}=500 \mathrm{~nm}$ and $\lambda_{2}=870 \mathrm{~nm}$.

When $\alpha$ tends towards zero, the size of the aerosols is often in the accumulation mode or in the coarse mode. Otherwise, when $\alpha$ increases, say around 1, the size of the aerosols tends towards very fine modes, even molecular dimensions. Generally, AERONET provides $\operatorname{AE}(\alpha)$ ranging from 0 (or even slightly negative) to 0.7-0.9 for mineral particles, from the desert zones to the area where they first mix with other aerosols, and ranging from 1.2 to 2.5 for urban pollution aerosols (Dubovik et al., 2002; Smirnov et al., 2002). When mixture is present, intermediate values may be found for $\mathrm{AE}$ : for example, $\alpha=0.95-1.02$ was measured in December 2000 by Sano et al. (2003) on Amami-Oshima island (Southern Japan), indicating a mixture of small and large particles; in the same experiment, these authors found a lower average of $\mathrm{AE} \sim 0.66$ when the desert dust fraction increased.

\section{- Beijing}

Figure 13a shows the time series of modelled AOT over Beijing and the corresponding AOT $(\tau)$ and $\operatorname{AE}(\alpha)$ AERONET data.

The AOT, during five days, is modelled as $\tau_{\text {Beijing }}=0.74 \pm 0.36$ (average \pm standard deviation), with a minimum of 0.22 before the first dust event, and a maximum of 1.99 on 27 April 2005, 18:00 UTC (28 April 2005, 02:00 LT) during the desert dust storm. In rather similar conditions, during spring 2001, Xia et al. (2005) found an average AOT $(500 \mathrm{~nm})$ ranging from $0.68 \pm 0.06$ to $0.81 \pm 0.70$. We are not far from this magnitude. Finally, our results very well agree with the monthly average of about 0.6 for April-May recorded by Qiu and Yang (2000) from 1980 to 1994.

AERONET data are diurnal observations, so we have constraint points only during approximately half of the studied days. However, the hourly observed shape during the local day (from 00:00 UTC to 12:00 UTC roughly) is roughly retrieved, day after day, by the modelled AOT. The observed and modelled values of 28 and
30 April 2005 are in agreement in the evening. Moreover, the modelled AOT lower than 0.6 before and after the dust events very well agree with the data of Beijing, but AERONET data for 29 April 2005 are higher than our estimates.

The AE observed in Beijing suggest that the hourly contribution calculated for each one of the two pollutant families (anthropogenic/natural) is relevant. In the hours before the first sandstorm, the AOT between 0.2 and 0.6 show a rather fairly polluted air composition, and the AE values (around 0.5) suggest that this pollution is a mixture of anthropogenic and mineral aerosols, but dominated by mineral dust. $24 \mathrm{~h}$ later, the $\mathrm{AE}$ are weak or even negative: the aerosol dominates in the coarse mode, which is a proof of the presence of the mineral plume, as simulated by the modelled AOT (Dust) partition of the total modelled AOT. On 29 April 2005, and even more on 30 April 2005, the increase in modelled anthropogenic contributions is clear and is underlined by the significant increase of the AE data. Lastly, after the second dust plume, on 1 May 2005, optical characteristics of a mixed aerosol ( $\alpha$ ranging between -0.2 and 0.5 ) are found.

As a conclusion, our simplified restitution of the optical characterization of the cycle of the natural and anthropogenic aerosols over Beijing seems to be relevant.

\section{- Dalanzadgad}

This AERONET site is located South of Mongolia, close to the emitting dust deserts. It is thus not surprising to model total AOT mainly due to the dust species (Fig. 13b).

Our AOT estimates correctly agree with the observed tendencies for the first dust event of 27-28 April 2005. On 28 April 2005, the low AE values $(\alpha \sim 0)$ confirm the prominence of mineral dust within the aerosol plume, but the modelled dust load itself is underestimated as observed AOT are twice more important than modelled AOT, with some hours in advance. Concerning the realtime discrepancies, we think that the short distance between the desert source and the AERONET site must be seen as the main cause of the delay between the extremes of observed and modelled AOT. The measurement site can detect some much localized epiphenomena that our spatio-temporal resolution cannot account for.

We correctly model a dust plume, over the Dalanzadgad area, during 29 April 2005. For the following days, we also correctly model the quick variations of AOT (although smoothed) with a dominant presence of mineral dust. 
(a)

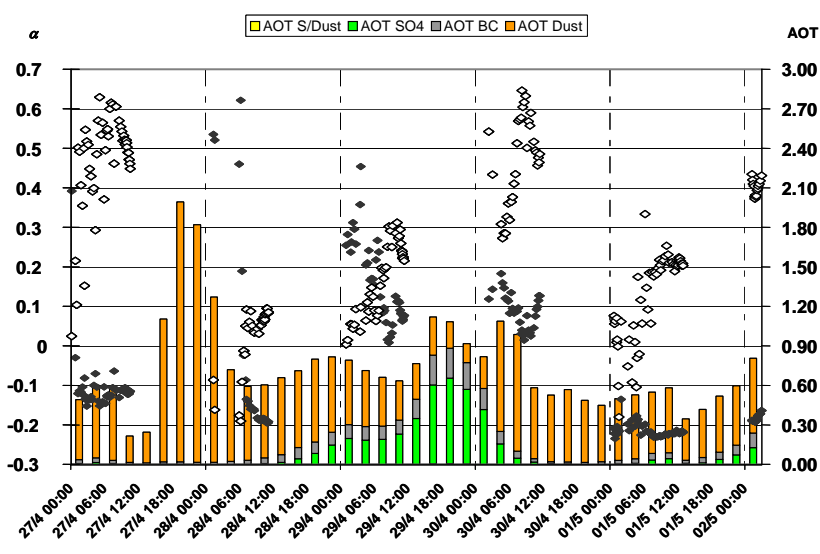

(c)

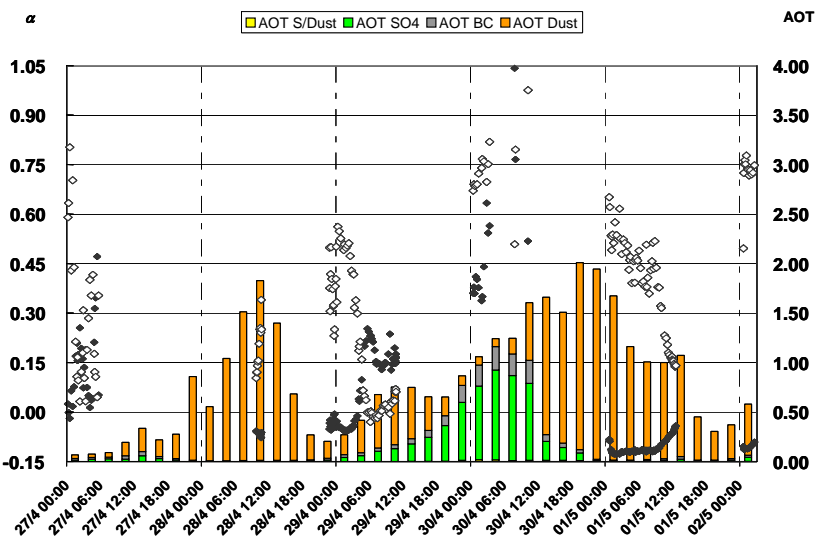

AOT

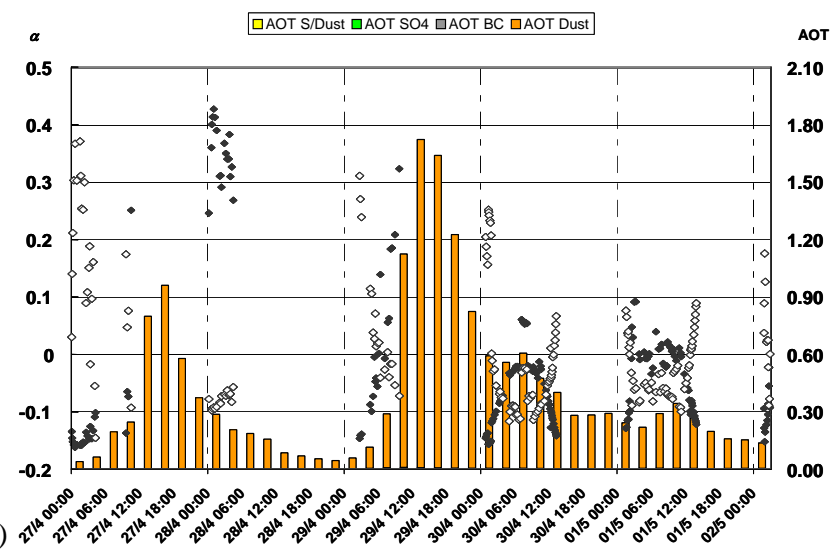

(b)

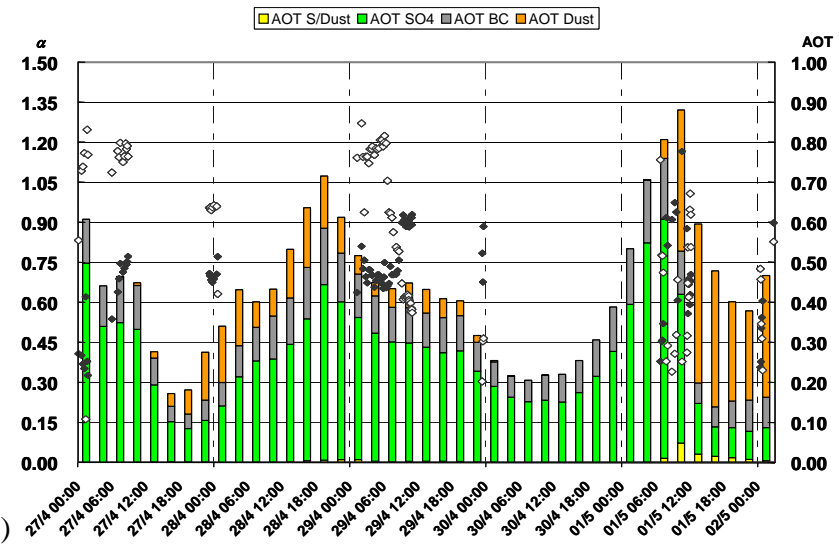

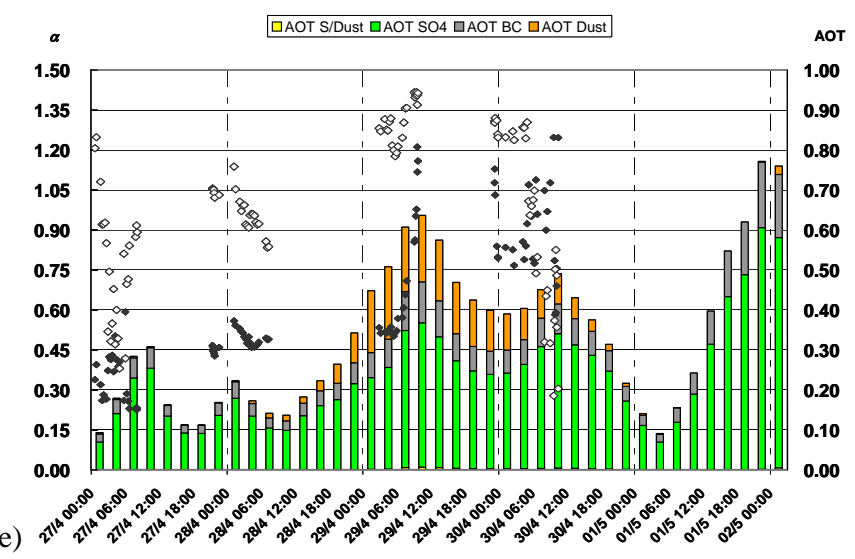

Fig. 13. Time series from 27 April 2005, 00:00 UTC to 2 May 2005, 00:00 UTC of the modelled AOT (right scale) including the respective contributions of dust (AOT(Dust) in orange), BC (AOT(BC) in grey), sulphates (AOT(SO4) in green) and "captured" $\mathrm{SO}_{2}$ (AOT(S/Dust) in yellow), and of the AERONET AOT (black diamonds, right scale) and Angström exponent $\alpha$ (white diamonds, left scale) for Beijing (China, a), Dalanzadgad (Mongolia, b), Liangning (China, c), Gwangju (Korea, d), and Osaka (Japan, e).

\section{- Liangning}

Liangning, located on the northern shore of the Bohai Sea, is polluted by local anthropogenic emissions, and by mineral dust coming from the close East Gobi deserts (Horqin, Otindag and Hulun Buir as well). Fig- ure 13c shows, for 27 and 28 April 2005, some modelled AOT with an opposite tendency compared to the few available data. AE data suggest a mineral mixed aerosol. We probably underestimate a dust plume crossing over Liangning during 27 April 2005, a hypothesis sustained by the MODIS imagery. Another possibility is that the model drives the dust plume further North than 
it actually was, so that the modelled dust plume never reaches Liangning. The last hypothesis is that the few level 1.0 data are inappropriate because of clouds over this place, which would be a limit for our methodology.

29 and 30 April 2005 are better described by the AERONET data. Figure 13c shows that the modelled AOT follow the observed tendency, as regards the time series and the order of magnitude. Modelled mineral load carried to Liangning on 30 April 2005 is underestimated, as the model reaches half of the observed AOT. This model delay conversely explains the overestimation of the AOT $24 \mathrm{~h}$ later with a major mineral composition whereas the AE suggests finer aerosol inside the plume. The model gives large quantities of sulphates on 30 April 2005, but we cannot further discuss this relative contribution to the total AOT because, as we said above, we underestimate the mineral contribution at the same time.

To sum up the Liangning case, the modelled AOT ranges between 0.07 and 2.01 (on average $\tau_{\text {Liangning }}=0.84 \pm 0.56$ ) and agree with the average orders of AOT observed over five days. However, even though the average orders of magnitude are relevant, our results exhibit time discrepancies compared to the actual events, which should incriminate the local dust source accuracy for the desert area close to Liangning.

- Gwangju and Osaka

Gwangju is located in South Korea. We display AOT and AE on Fig. 13d. The AOT (SO4) is prominent in the total AOT since it contributes on average to $60 \%$ of the total average AOT: $\tau_{\text {Gwangju }}=0.43 \pm 0.17$. BC also continuously takes a significant part in the total AOT (5 days average: $21 \%$ ). The very absorbing nature of $\mathrm{BC}$, even compared to the $\mathrm{SO}_{4}^{2-}$, is counterbalanced by the much higher concentrations of the latter one compared to the former one.

Here, a very satisfactory agreement can be noted between modelled and AERONET AOT, in the time variations and in magnitude as well. Moreover, the two dust episodes are correctly retrieved by the model. When the two dust events occur over the Korean peninsula (29 April 2005 and from 1 May 2005), the AOT (Dust) is significant and AE tends to decrease. Note the (small) contribution of coating $\mathrm{SO}_{4}^{2-}$ on dust around 1 May 2005, 12:00 UTC (referred to as AOT (S/Dust)).

The same comparisons are also applicable, as a whole, to the Osaka results (Fig. 13e), over Japan, except for the tendency observed on 1 May 2005 (because of a lack of observational data). Average AOT over the 5 days is $\tau_{\text {Osaka }}=0.34 \pm 0.19$ with extreme values ranging between 0.09 and 0.77 . With our estimates, AOT (SO4) contribution is $71 \%$ of the average total AOT. The AOT peak (29 to 30 April 2005) occurs $24 \mathrm{~h}$ later than the same peak modelled over the continent, due to transport duration.

We can thus easily give the orders of magnitude for the relative AOT contributions in $\mathrm{BC}$ and sulphates on the two cities located in Korea and Japan, both far away from the sources of mineral pollution, but themselves acting as sources of anthropogenic pollutants. Over 5 days, the contributions of BC and sulphates are more clearly dissociated in Osaka, where sulphates contribute four times more than $\mathrm{BC}$ to the total AOT: AOT (SO4)/AOT (BC)=0.24/0.06 4. This ratio is also modelled over Gwangju: AOT (SO4)/AOT $(B C)=0.26 / 0.09 \sim 3$. Our estimates in Korea and Japan range between those of Aoki et al. (2005): AOT (SO4)/AOT $(\mathrm{BC})=0.075 / 0.04 \sim 19$, concerning the overall Japan, and the order of magnitude of 2, evaluated during April-May, over the cities of Tsukuba, Niigata and Sapporo (Japan) by Takemura et al. (2001). Lastly, we find that, even in case of desert dust transported from the continent, the total average AOT at Gwangju and Osaka is mainly of anthropogenic origin, which locally agrees with the global assessment of Takemura et al. (2003) about the Aerosol Characterization Experiments (ACE) - Asia area.

\section{Conclusions}

The objective of our work was to develop the modelling of the distribution and variations of the natural and anthropogenic aerosols in an area appearing increasingly implied in pollution problems: Eastern Asia. The interest of this approach is to build a usable tool to easily assess the real-time chemical and optical consequences of these pollutants of various origins.

In a former paper (Lasserre et al., 2005), we built a mineral dust source according to the Dust Production Model (DPM) of Marticorena and Bergametti (1995) and Marticorena et al. (1997a; 1997b). We present the specific elements of the East-Asian desert mineral source in China and Mongolia, coupled online with the RAMS model. This coupling enables us to simulate desert dust events, including their rising, transport and deposition (dry and wet).

The results of the case study of dust plumes observed in spring 2005 over China, Korea and Japan show the relevance of our numerical tool, for the emitted dust fluxes and the main transport pathways. Indeed, we modelled the surface concentrations and the column load of mineral dust and the results agree with the visibility analysis and the in situ observations. In order to consider the time heterogeneity of the mixed pollution issue, we present here a "realtime" case study. The limits of the model are seen in terms of offsets between results and observations, but the shorttime tendencies are fairly well reproduced as a whole. The 
surface concentrations are in good agreement with observations in China (Hohhot and Beijing). The study of the vertical profiles shows that dust transport takes place below 3000-4000 ma.g.l. These profiles present very quick and clear variations in structure, alternating between homogeneous and stratified forms. The modelled profiles above Hohhot and Beijing are confirmed by local LIDAR data of backscattering intensities and depolarisation ratio on a semi quantitative approach.

We choose aerosols ( $\mathrm{BC}$ and sulphates) along with an anthropogenic pollution gas ( $\mathrm{SO}_{2}$, a sulphate precursor) in addition to the mineral aerosols, in order to model and to easily interpret the coexistence of these species and their consequences, particularly the optical signatures of aerosols. For anthropogenic pollutant emissions, GEIA (BC) and EDGAR $\left(\mathrm{SO}_{2}\right)$ databases are used. Dynamic parameterizations (deposition rates) and the chemistry of the anthropogenic pollutants are drastically simplified as compared to other studies reviewed in the ACPD version of this paper (Lasserre et al., 2007). Our parameterizations are simple, but they appear sufficient to model the atmospheric cycles.

We describe the pollution observed on the quasicontinuum of some megacities of East China and Korea, and above the seas which separate them from Japan. Maximum surface concentrations of several tens of $\mu \mathrm{g} \mathrm{m}^{-3}$ of BC and of $\mathrm{SO}_{4}^{2-}$ and several hundred of $\mu \mathrm{g} \mathrm{m}^{-3}$ of $\mathrm{SO}_{2}$ are modelled over large cities. Moreover, we show that dust aerosols initially mix with the anthropogenic ones in the frontal region of desert dust plumes. Next, the mixing preferentially takes place with the mineral particles already located above the sources of anthropogenic pollution. Afterwards, these mixed particles move over the sea to Japan, resulting in pollution events of continental origin.

Using AERONET measurements above five sites located along the aerosols pathways, we test our estimates of Aerosol Optical Thickness (AOT). The surface extinction for BC, sulphates (free and captured on dust) and mineral particles were derived from literature: $12 \mathrm{~m}^{2} \mathrm{~g}^{-1}, 8 \mathrm{~m}^{2} \mathrm{~g}^{-1}$ and $1.2 \mathrm{~m}^{2} \mathrm{~g}^{-1}$ respectively. The total AOT, calculated as the sum of the contributions of the four species, is then compared with the AERONET AOT real-time data. We also display the AERONET Angstrom Exponent (AE), which helps characterizing the nature of aerosols. The orders of magnitude of the modelled AOT are coherent with the orders of magnitude of the observations. We particularly retrieve a realistic evolution of AOT as compared with the AERONET time-series from 27 April 2005 to 2 May 2005. We also show that the modelled relative abundances in aerosols are often compatible with the magnitudes of the AE.

Our rather good model results suggest that our simplified tool is suitable for real-time aerosol studies in a complex environment: its use involves rather low CPU consumption even though it takes into account the complete atmospheric cycle of mineral dust. In a pollution context dominated by mineral dust aerosols (e.g. East Asia, Africa), the anthropogenic part of the tool just needs realistic emission databases of the main pollutants without being extremely detailed so that it can be used in a large set of applications, e.g. regional climatic impact of aerosols, forecasting and public health issues, as, for instance, in China, in the African Sahelian zone or in Australia.

Acknowledgements. Our work was supported by funding from the French Centre National de la Recherche Scientifique (Programme National de Chimie Atmosphérique). This work makes use of the RAMS model, which was developed under the support of the National Science Foundation (NSF) and the Army Research Office (ARO). Computer resources were partly provided by CINES (Centre Informatique National de l'Enseignement Supérieur). We thank Brent Holben for his effort in establishing and maintaining the AERONET Dalanzadbag site. We thank Zhanqing Li for the Liangning site AERONET data (funded through the East-Asian Study of Tropospheric Aerosols - An International Regional experiment (EAST-AIRE) project). We are also extremely grateful to Itaru Sano for the Osaka AERONET data and Hong-Bin Chen and Philippe Goloub for the Beijing AERONET data. The data used in this study (Fig. 4) were acquired as part of the NASA's Earth Science Enterprise. The algorithms were developed by the MODIS Science Teams. The data were processed by the MODIS Adaptive Processing System (MODAPS) and Goddard Distributed Active Archive Center (DAAC), and are archived and distributed by the Goddard DAAC. We thank C. Mallet-Germa, E. Edison-Woo and J. Chomilier to have corrected the english language. We wish to thank the computer team of the Laboratoire de Physique de l'Atmosphère (LaMP) of the Université Blaise Pascal (France): A.-M. Lanquette, S. Banson and Ph. Cacault.

Edited by: M. G. Lawrence

\section{References}

Adams, J. W., Rodriguez, D., and Cox, R. A.: The uptake of $\mathrm{SO}_{2}$ on Saharan dust: A flow tube study, Atmos. Chem. Phys., 5, 26792689, 2005,

http://www.atmos-chem-phys.net/5/2679/2005/.

Alfaro, S. C., Gaudichet, A., Gomes, L., and Maille, M.: Mineral aerosol production by wind erosion: Aerosol particle sizes and binding energies, Geophys. Res. Lett. 25, 991-994, 1998.

Alfaro, S. C. and Gomes, L.: Modeling mineral aerosol production by wind erosion: Emission intensities and aerosol distributions in source areas, J. Geophys. Res., 106, 18 075-18 084, 2001.

Angström, A.: The parameters of atmospheric turbidity, Tellus, 16, 64-75, 1964.

Aoki, I., Kurosaki, Y., Osada, R., Sato, T., and Kimura, F.: Dust storms generated by mesoscale cold fronts in the Tarim Basin, Northwest China, Geophys. Res. Lett., 32, L06807, doi:10.1029/2004GL021776, 2005.

Carmichael, G. R., Hayami, H., Calori, G., Uno, I., Cho, S. Y., Engardt, M., Kim, S.-B., Ichikawa, Y., Ikeda, Y., Ueda, H., and Amann, M.: Model Intercomparison Study of Long Range Transport and Sulfur deposition in East Asia (MICS-ASIA), Water Air Soil Poll., 130 (1-4), 51-62, doi:10.1023/A:1012291200633, 2001. 
Cautenet, G., Guillard, F., Marticorena, B., Bergametti, G., Dulac, F., and Edy, J.: Modelling of the Saharan dust event, Meteorol. Z., 9, 221-230, 2000.

Cautenet, S. and Lefeivre, B.: Contrasting behavior of gas and aerosol scavenging in convective rain: A numerical and experimental study in the African equatorial forest, J. Geophys. Res., 99(D6), 13013-13024, 1994.

Chylek, P., Videen, G., Ngo, D., Pinnick, R. G., and Klett, J. D.: Effect of black carbon on the optical properties and climate forcing of sulfate aerosols, J. Geophys. Res., 100(D8), 6325-6332, 1995.

Cotton, W. R., Pielke, R. A., Walko, R. L., Liston, G. E., Tremback, C. J., Jiang, H., McAnelly, R. L., Harrington, J. Y., Nicholls, M. E., Carrio, G. G., and McFadden, J. P.: Rams 2001: Current status and future directions, Meteorol. Atmos. Phys., 82, 5-29, 2003.

Dentener, F. J., Carmichael, G. R., Zhang, Y., Lelieveld, J., and Crutzen, P.: The role of mineral aerosol as a reactive surface in the global troposphere, J. Geophys. Res., 101(D17), 22 869$22889,1996$.

Dubovik, O., Holben, B. N., Eck, T. F., Smirnov, A., Kaufman, Y. J., King, M. D., Tanré, D., and Slutsker, I.: Variability of Absorption and Optical Properties of Key Aerosol Types Observed in Worldwide Locations, J. Atmos. Sci., 59(3), 590-608, 2002.

Guo, J., Rahn, K. A., and Zhuang, G.: A mechanism for the increase of pollution elements in dust storms in Beijing, Atmos. Environ., 38(6), 855-862, 2004.

Han, Z., Ueda, H., Matsuda, K., Zhang, R., Arao, K., Kanai, Y., and Hasome, H.: Model study on particle size segregation and deposition during Asian dust events in March 2002, J. Geophys. Res., 109, D19205, doi:10.1029/2004JD004920, 2004.

Hatakeyama, S., Murano, K., Bandow, H., Mukai, H., and Akimoto, H.: High concentration of $\mathrm{SO}_{2}$ observed over the sea of Japan, Terr. Atmos. Ocean. Sci., 6(3), 403-408, 1995.

Holben, B. N., Eck, T. F., Slutsker, I., Tanré, D., Buis, J. P., Setzer, A., Vermote, E., Reagan, J. A., Kaufman, Y. J., Nakajima, T., Lavenu, F., Jankowiak, I., and Smirnov, A.: AERONET A Federated Instrument Network and Data Archive for Aerosol Characterization, Remote Sens. Environ., 66, 1-16, 1998.

Jacobson, M. J.: Strong radiative heating due to the mixing state of black carbon in atmospheric aerosols, Nature, 409, 695-697, 2001.

Kunhikrishnan, T., Lawrence, M. G., von Kuhlmann, R., Richter, A., Ladstätter-Weißenmayer, A., and Burrows, J. P.: Analysis of tropospheric NOx over Asia using the model of atmospheric transport and chemistry (MATCH-MPIC) and GOME-satellite observations, Atmos. Environ., 38(4), 581-596, 2004.

Lasserre, F., Cautenet, G., Alfaro, S. C., Gomes, L., Rajot, J.-L., Lafon, S., Gaudichet, A., Chatenet, B., Maille, M., Cachier, H., and Zhang, X. Y.: Development and validation of a simple mineral dust source inventory suitable for modelling in North Central China., Atmos. Environ., 39(21), 3831-3841, 2005.

Lasserre, F., Cautenet, G., Bouet, C., Dong, X., Kim, Y. J., Sugimoto, N., Matsui, I., and Shimizu, A.: A comprehensive modelling way for assessing real-time mixings of mineral and anthropogenic pollutants in East Asia, Atmos. Chem. Phys. Discuss., 7, 11895-11971, 2007,

http://www.atmos-chem-phys-discuss.net/7/11895/2007/.

Laurent, B., Marticorena, B., Bergametti, G., Chazette, P., Maig- nan, F., and Schmechtig, C.: Simulation of the mineral dust emission frequencies from desert areas of China and Mongolia using an aerodynamic roughness length map derived from the POLDER/ADEOS 1 surface products, J. Geophys. Res., 110, D18S04, doi:10.1029/2004JD005013, 2005.

Li, C., Mao, J., and Lau, K.-H.: Research on air pollution in Beijing and its surroundings with MODIS aerosol products, Optical Remote Sensing of the Atmosphere and Clouds III. Proceedings of the SPIE, 4891, 419-430, 2003.

Liu, X., Zhu, J., Van Espen, P., Adams, F., Xiao, R., Dong, S., and $\mathrm{Li}$, Y.: Single particle characterization of spring and summer aerosols in Beijing: Formation of composite sulfate of calcium and potassium, Atmos. Environ., 39(36), 6909-6918, 2005.

Ma, C.-J., Tohno, S., Kasahara, M., and Hayakawa, S.: Properties of individual Asian dust storm particles collected at Kosan, Korea during ACE-Asia, Atmos. Environ., 38(8), 1133-1143, 2004.

Marticorena, B. and Bergametti, G.: Modeling the atmospheric dust cycle: 1-Design of a soil derived production scheme, J. Geophys. Res., 100, 16415-16430, 1995.

Marticorena, B., Bergametti, G., Aumont, B., Callot, Y., N'Doumé, C., and Legrand, M.: Modeling the atmospheric dust cycle: 2Simulations of Saharan dust sources, J. Geophys. Res., 102, 4387-4404, 1997a.

Marticorena, B., Bergametti, G., Gillette, D. A., and Belnap, J.: Factors controlling threshold friction velocity in semi-arid and arid areas of the United States, J. Geophys. Res., 102, $23277-$ $23287,1997 \mathrm{~b}$.

McNaughton, C. S., Clarke, A. D., Howell, S. G., Moore II, K. G., Brekhovkikh, V., Weber, R. J., Orsini, D. A., Covert, D. S., Buzorius, G., Brechtel, F. J., Carmichael, G. R., Tang, Y., Eisele, F. L., Mauldin, R. L., Bandy, A. R., Thornton, D. C, and Blomquist, B.: Spatial distribution and size evolution of particles in Asian outflow: Significance of primary and secondary aerosols during ACE-Asia and TRACE-P, J. Geophys. Res., 109, D19S06, doi:10,1029/2003JD003528, 2004.

Menon, S., Hansen, J., Nazarenko, L., and Luo, Y.: Climate effects of black carbon aerosols in China and India, Science, 297(5590), 2250-2253, 2002.

Minvielle, F., Aspects physiques et radiatifs du cycle atmosphérique des aerosols : étude numérique sur l'Océan Indien (expérience INDOEX), Thèse de doctorat (Physique de l'Atmosphère), Université Blaise Pascal (U.F.R. de Recherche Scientifique et Technique, Laboratoire de Météorologie Physique), 2003.

Minvielle, F., Cautenet, G., Andreae, M. O., Lasserre, F., Foret, G., Cautenet, S., Léon, J.-F., Mayol-Bracero, O. L., Gabriel, R., Chazette, P., and Roca, R.: Modeling the transport of aerosols during INDOEX 1999 and comparison with experimental data. Part 1: carbonaceous aerosol distribution, Atmos. Environ., 38(12), 1811-1822, 2004a.

Minvielle, F., Cautenet, G., Lasserre, F., Foret, G., Cautenet, S., Léon, J.-F., Andreae, M. O., Mayol-Bracero, O. L., Gabriel, R., Chazette, P., and Roca, R.: Modeling the transport of aerosols during INDOEX 1999 and comparison with experimental data. Part 2: continental aerosol and their optical depth, Atmos. Environ., 38(12), 1823-1837, 2004b.

Novakov, T., Chang, S. G., and Harker, A. B.: Sulfates as pollution particles: Catalytic formation on carbon (soot) particles, Science, 186, 259-261, 1974.

Olivier, J. G., Bouwman, A. F., Van der Maas, C. W. M., Berdowski, 
J. J. M., Veldt, C., Bloos, J. P. J., Visschedijk, A. J. H., Zandveld, P. Y. J., and Haverlag, J. L.: Description of EDGAR Version 2.0. A set of global emission inventories of greenhouse gases and ozone-depleting substances for all anthropogenic and most natural sources on a per country basis and on $1^{\circ} \times 1^{\circ}$ grid, RIVM/TNO report. RIVM, Bilthoven, RIVM report n. 771060 002. (TNO MEP report nr. R96/119), 1996.

Pradelle F. and Cautenet, G.: Radiative and microphysical interactions between marine stratocumulus clouds and Saharan dust 2. Modeling, J. Geophys. Res.,107(D19), 4413, doi:10.1029/2000JD000156, 2002.

Qiu, J. and Yang, L.: Variation characteristics of atmospheric aerosol optical depths and visibility in North China during 19801994, Atmos. Environ., 34, 603-609, 2000.

Reddy, M. S., Boucher, O., Balkanski, Y., and Schultz, M.: Aerosol optical depths and direct radiative perturbations by species and source type, Geophys. Res. Lett., 32, L12803, doi:10.1029/2004GL021743, 2005.

Sano, I., Mukai, S., Okada, Y., Holben, B. N., Ohta, S., and Takamura, T.: Optical properties of aerosol during APEX and ACE-Asia experiments, J. Geophys. Res., 108(D23), 8649, doi:10.1029/2002JD003263, 2003.

Shi, Z. B., Shao, L. Y., Jones, T. P., Whittaker, A. G., Lu, S. L., Berube, K. A., He, T. O., and Richards, R. J.: Characterization of airborne individual particles collected in an urban area, a satellite city and a clean air area in Beijing, 2001. Atmos. Environ., 37(29), 4097-4108, 2003.

Shimizu, A., Sugimoto, N., Matsui, I., Arao, K., Uno, I., Murayama, T., Kagawa, N., Aoki, K., Uchiyama, A., and Yamazaki, A.: Continuous observations of Asian dust and other aerosols by polarization lidars in China and Japan during ACE-Asia, J. Geophys. Res., D19S17, doi:10.1029/2002JD003253, 2004.

Smirnov, A., Holben, B. N., Dubovik, O., O’Neill, N. T., Eck, T. F., Westphal, D. L., Goroch, A. K., Pietras, C., and Slutsker, I.: Atmospheric aerosol optical properties in the Persian Gulf, J. Atmos. Sci., 59(3), 620-634, 2002.

Sun, J. M., Zhang, M., and Liu, T. S.: Spatial and temporal characteristics of dust storms in China and its surrounding regions, 1960-1999: Relations to source area and climate, J. Geophys. Res., 106(D10), 10325-10333, 2001.

Takemura, T., Nakajima, T., Nozawa, T., and Aoki, K.: Simulation of future aerosol distribution, radiative forcing, and long-range transport in east Asia, J. Meteor. Soc. Jpn, 79(6), 1139-1155, 2001.

Takemura, T., Nakajima, T., Higurashi, A., Ohta, S., and Sugimoto, N.: Aerosol distributions and radiative forcing over the Asian Pacific region simulated by Spectral Radiation Transport Model for Aerosol Species (SPRINTARS), J. Geophys. Res., 108(D23), 8659, doi:10.1029/2002JD003210, 2003.
Tang, Y., Carmichael, G. R., Kurata, G., Uno, I., Weber, R. J., Song, C.-H., Guttikunda, S. K., Woo, J.-H., Streets, D. G., Wei, C., Clarke, A. D., Huebert, B., and Anderson, T. L.: Impacts of dust on regional tropospheric chemistry during the ACE-Asia experiment: A model study with observations, J. Geophys. Res., 109, D19S21, doi:10,1029/2003JD003806, 2004.

Trijonis, J. C., Maim, W. C., Pitchford, M., White, W. H., Charlson, R. J., and Husar, R.: Visibility: Existing and Historical Conditions - Causes and Effects. Acidic Deposition: State of Science and Technology Report No. 24, National Acid Precipitation Assessment Program, Washington, D.C., 1990.

Uno, I., Carmichael, G. R., Streets, D., Satake, S., Takemura, T., Woo, J.-H., Uematsu, M., and Ohta, S.: Analysis of surface black carbon distributions during ACE-Asia using a regional-scale aerosol model, J. Geophys. Res., 108(D23), 8636, doi:10,1029/2002JD003252, 2003.

Wang, C.: A modeling study on the climate impacts of black carbon aerosols, J. Geophys. Res., 109, D03106, doi:10.1029/2003JD004084, 2004.

Wang, Y., Zhuang, G., Zhang, X., Huang, K., Xu, C., Tang, A., Chen, J., and An, Z.: The ion chemistry, seasonal cycle, and sources of PM2.5 and TSP aerosol in Shanghai, Atmos. Environ., 40(16), 2935-2952, 2006.

Watson, J. G., Chow, J. C., Lowenthal, D. H., Cahill, C. F., Blumenthal, D. L., Richards, L. W., and Jorge, H.G.: Aerosol chemical and optical properties during the Mt. Zirkel Visibility Study. J. Environ. Qual., 30(4), 1118-1125, 2001.

Xia, X.-A., Chen, H.-B., Wang, P.-C., Zong, X.-M., Qiu, J.-H., and Goulomb, P.: Aerosol properties and their spatial and temporal variations over North China in spring 2001, Tellus, 57(B), 28-39, 2005.

Xu, Y., and Carmichael, G. R.: Modeling the dry deposition velocity of sulfur dioxide and sulfate in Asia, J. Appl. Meteorol., 37(10), 1084-1099, 1998.

Yang, J., Wang, J., Cao, D., Ge, C., and Gao, S.: Pollution control strategy based on performance in power sector, CRAES Research Report, 2002.

Zhang, D., Zang, J., Shi, G., Iwasaka, Y., Matsuki, A., and Trochkine, D.: Mixture state of individual Asian dust particles at a coastal site of Qingdao, Atmos. Environ., 37(28), 3895-3901, 2003.

Zhang, X. Y., Gong, S. L., Shen, Z. X., Mei, F. M., Xi, X. X., Liu, L. C., Zhou, Z. J., Wang, D., Wang, Y. Q., and Cheng, Y.: Characterization of soil dust aerosol in China and its transport and distribution during 2001 ACE-Asia: 1. Network observations, J. Geophys. Res., 108(D9), 4261, doi:10.1029/2002JD002632, 2003b. 